\title{
Postsynthetic inner-surface functionalization of the
}

\section{highly stable zirconium-based metal-organic}

\section{framework DUT-67}

Franziska Drache, ${ }^{\mathrm{a}}$ Volodymyr Bon, ${ }^{\mathrm{a}}$ Irena Senkovska, ${ }^{\mathrm{a}}$ Claudia Marschelke, ${ }^{\mathrm{b}}$ Alla

Synytska, ${ }^{\mathrm{b}}$ and Stefan $\mathrm{Kaskel}^{\mathrm{c}}$

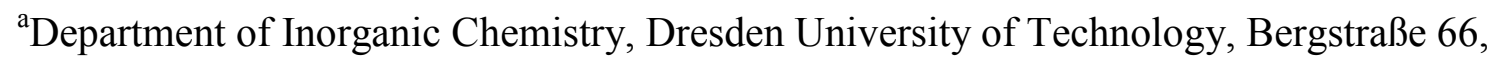
01062 Dresden, Germany

${ }^{\mathrm{b}}$ Leibniz-Institut für Polymerforschung Dresden e.V., Hohe Str. 6, 01069 Dresden, Germany

Table of content

Section S1. Physisorption data

Section S2. Powder X-ray data

Section S3. Thermogravimetric analysis (TGA) and differential thermal analysis (TGA)

Section S4. NMR data

Section S5. Kinetic of the modulator exchange 
Section S1. Physisorption data

S.1.1 $\mathrm{N}_{2}$ physisorption isotherms

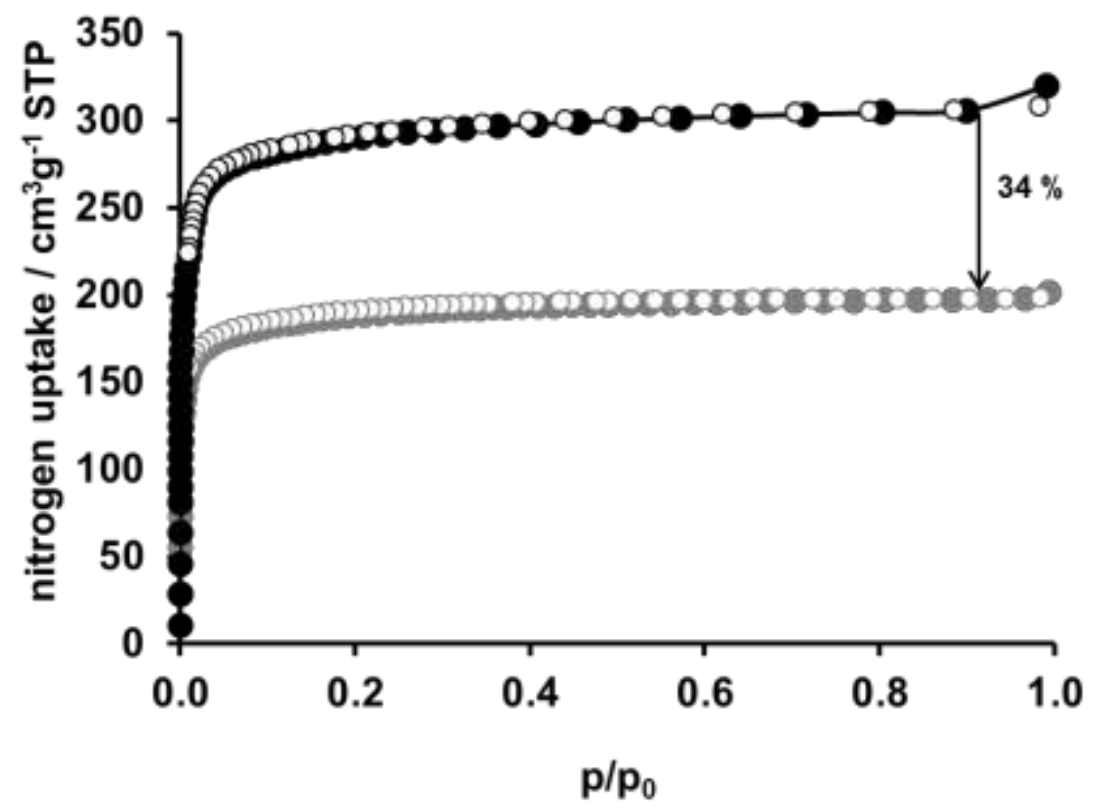

Figure S 1. Nitrogen adsorption (solid symbols) and desorption (blank symbols) isotherms at $77 \mathrm{~K}$ on DUT-67-Fa before (black symbols) and after water desorption (grey symbols).

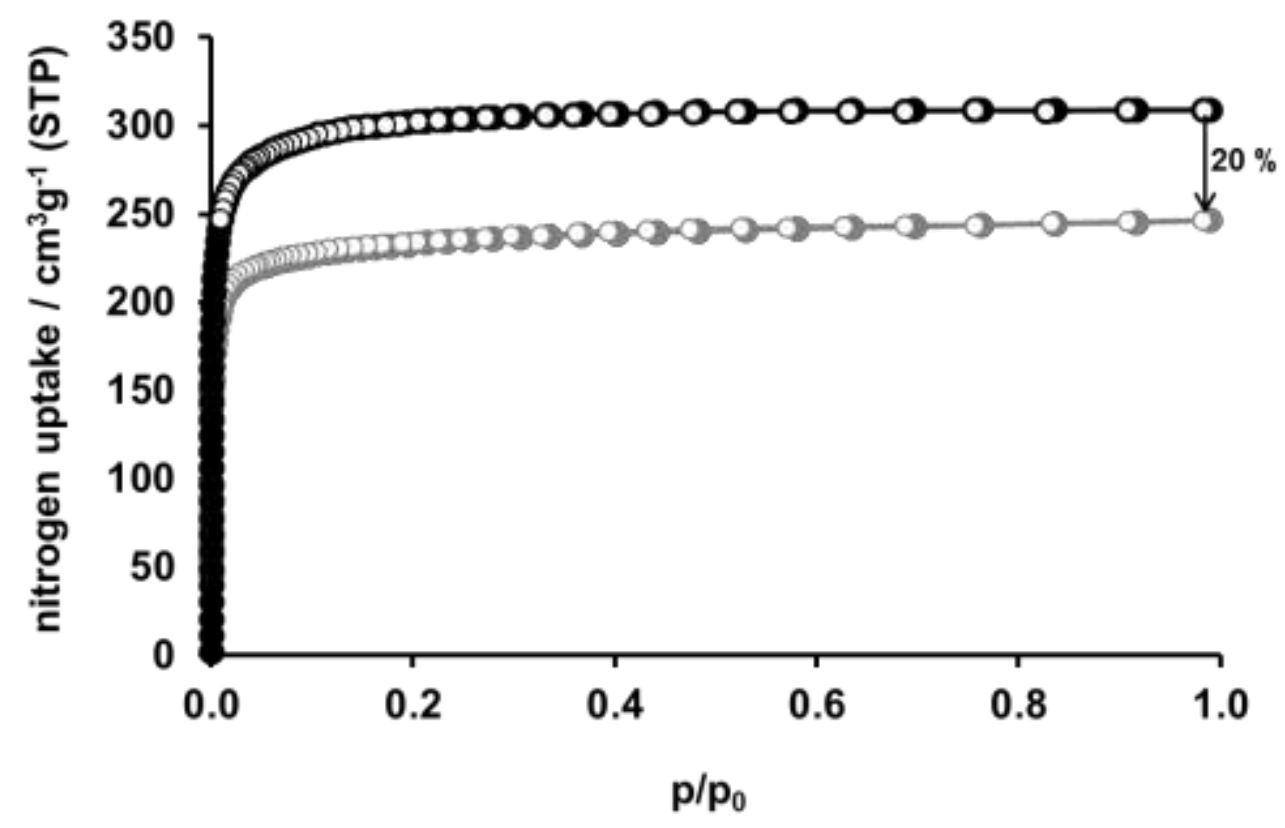

Figure S 2. Nitrogen adsorption (solid symbols) and desorption (blank symbols) isotherms at 77 K on DUT-67Ac before (black symbols) and after water desorption (grey symbols). 


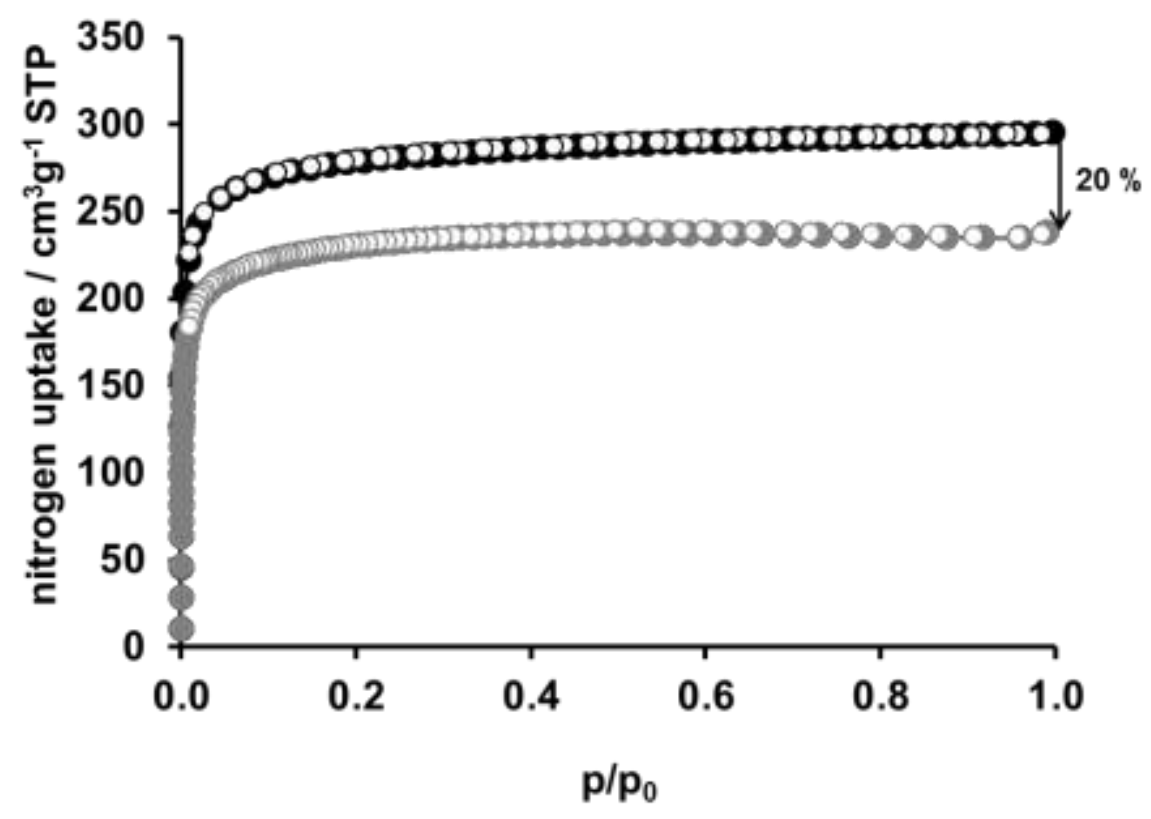

Figure S 3. Nitrogen adsorption (solid symbols) and desorption (blank symbols) isotherms at $77 \mathrm{~K}$ on DUT-67-Pa before (black symbols) and after water desorption (grey symbols).

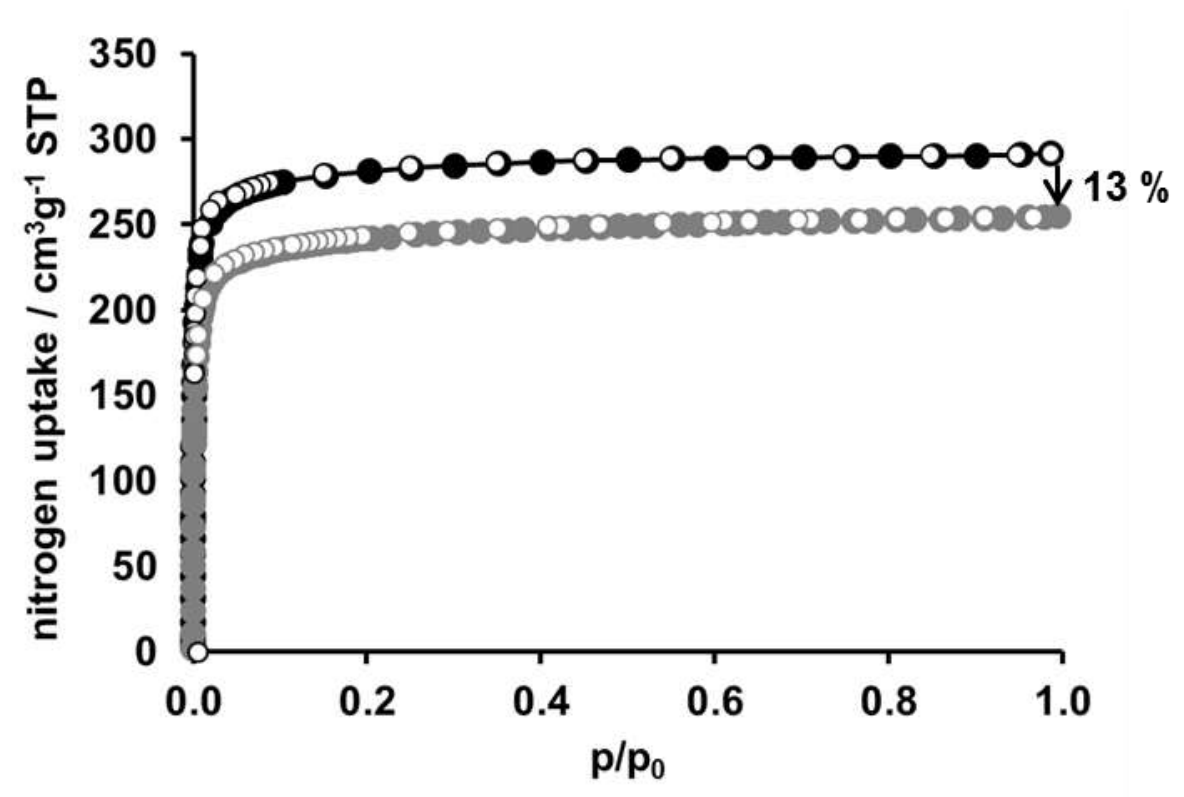

Figure S 4. Nitrogen adsorption (solid symbols) and desorption (blank symbols) isotherms at $77 \mathrm{~K}$ of DUT-67-Tfmba before (black symbols) and after water desorption (grey symbols). 


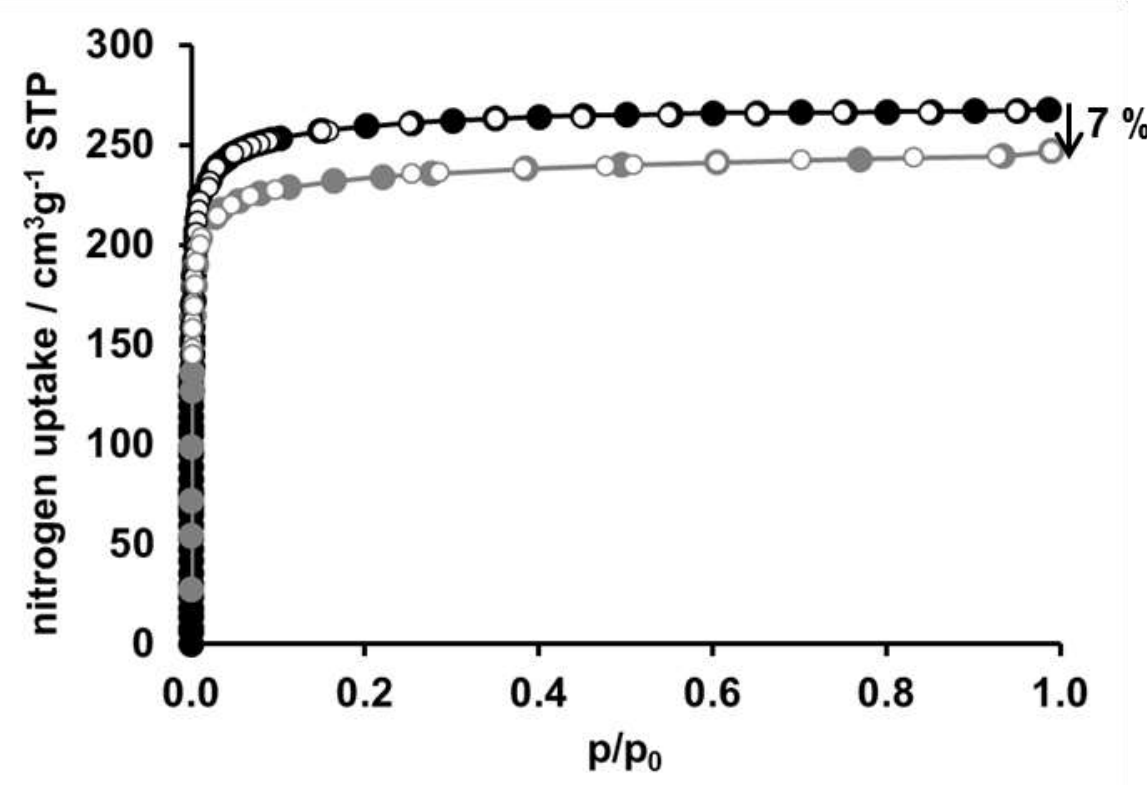

Figure S 5. Nitrogen adsorption (solid symbols) and desorption (blank symbols) isotherms at $77 \mathrm{~K}$ of DUT-67-Tfa before (black symbols) and after water desorption (grey symbols).

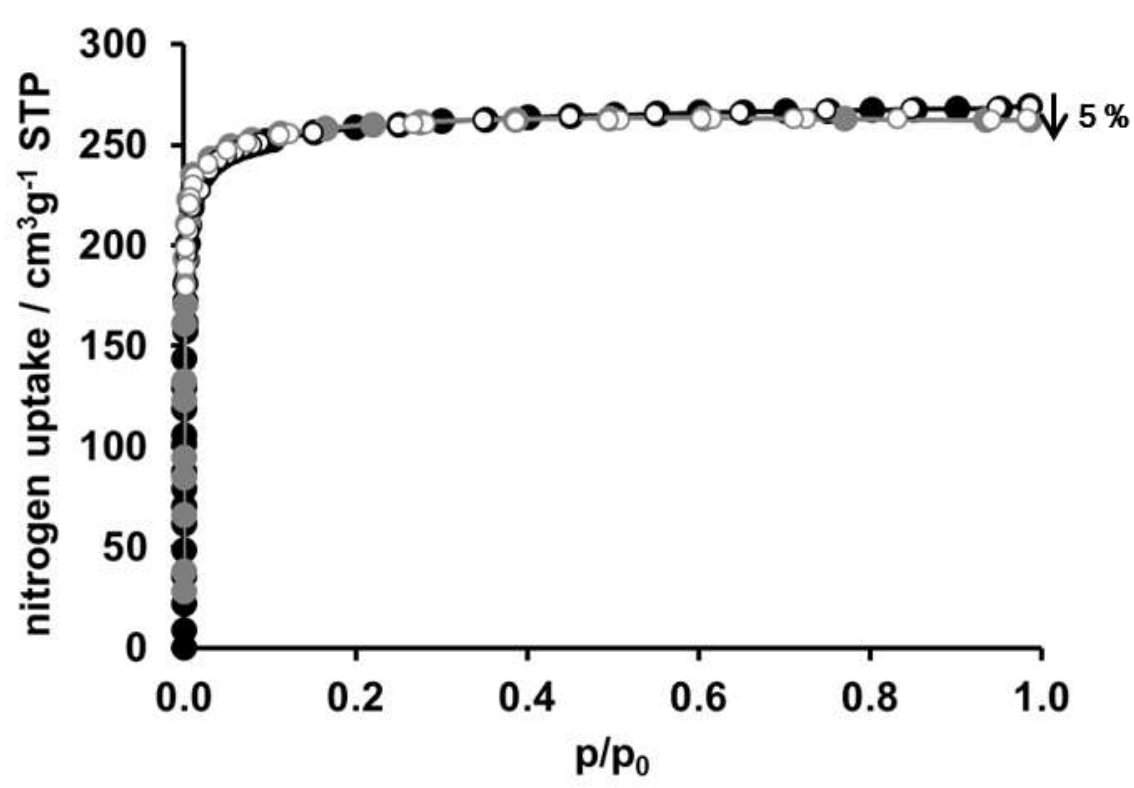

Figure S 6. Nitrogen adsorption (solid symbols) and desorption (blank symbols) isotherms at $77 \mathrm{~K}$ on DUT-67-Pfba before (black symbols) and after water desorption (grey symbols). 


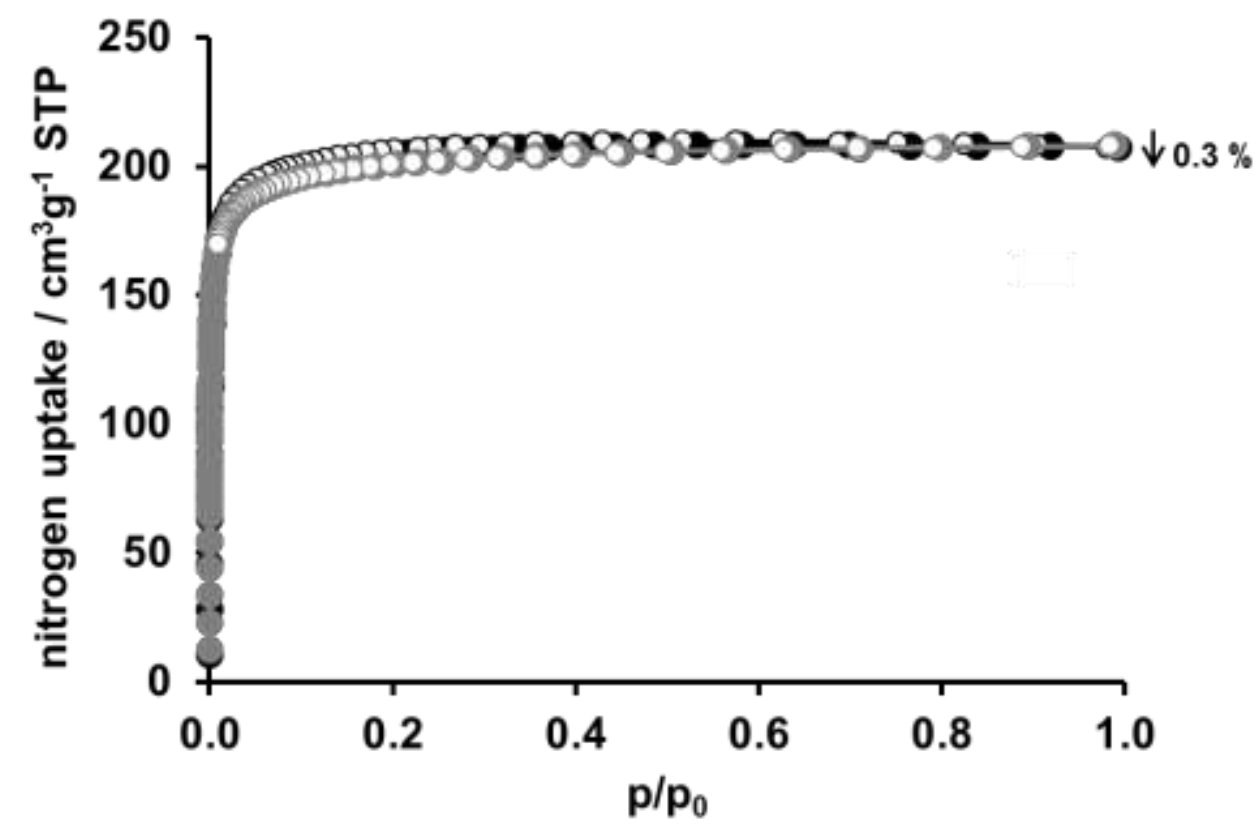

Figure S 7. Nitrogen adsorption (solid symbols) and desorption (blank symbols) isotherms at $77 \mathrm{~K}$ on DUT-67-Pfoa before (black symbols) and after water desorption (grey symbols). 


\section{S.1.2 DFT pore size distribution calculations from $\mathrm{N}_{2}$ isotherms}

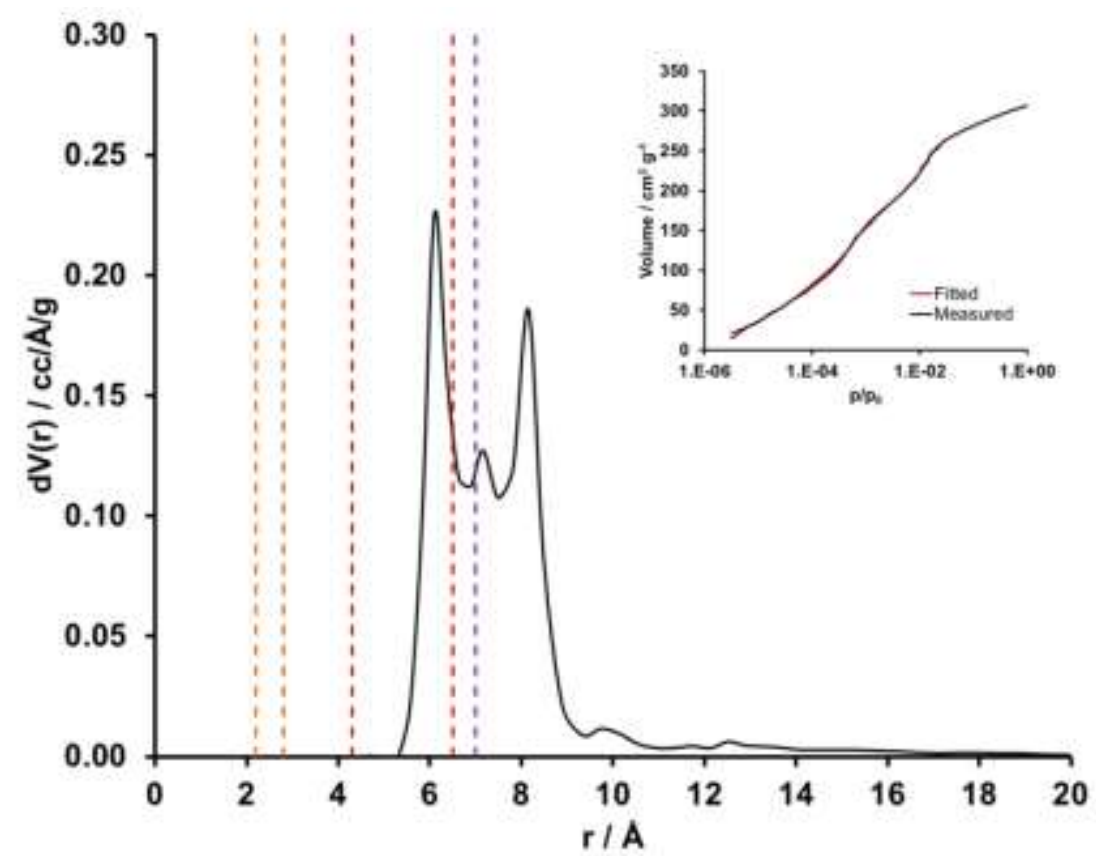

Figure S 8. DFT pore size distribution of DUT-67-Fa. The dotted lines correspond to the pore sizes calculated from zeo ++ (yellow line: octahedral pore A, red line: cuboctahedral pore B with modulator, purple line: cuboctahedral pore $\mathrm{C}$ without modulator). In the right corner, the fit of the calculated and the measured isotherms is presented.

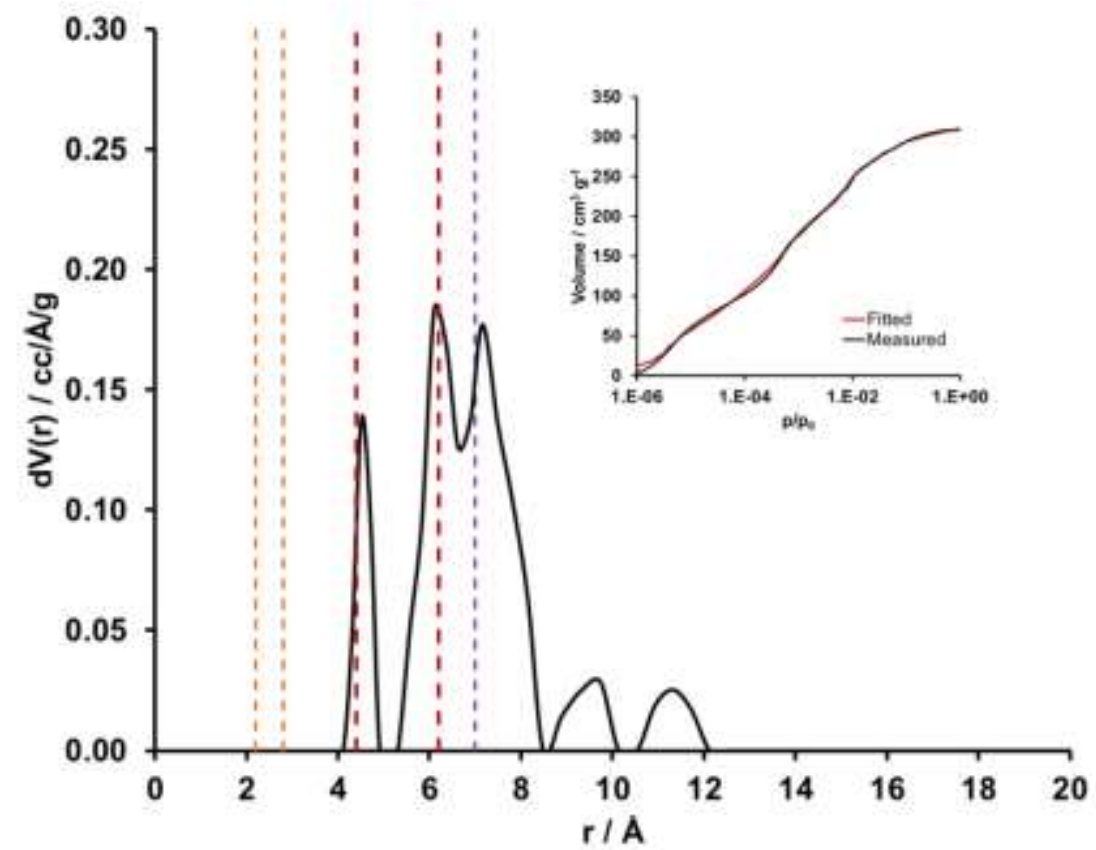

Figure S 9. DFT pore size distribution of DUT-67-Ac. The dotted lines correspond to the pore sizes calculated from zeo ++ (yellow line: octahedral pore A, red line: cuboctahedral pore B with modulator, purple line: cuboctahedral pore $\mathrm{C}$ without modulator). In the right corner, the fit of the calculated and the measured isotherms is presented. 


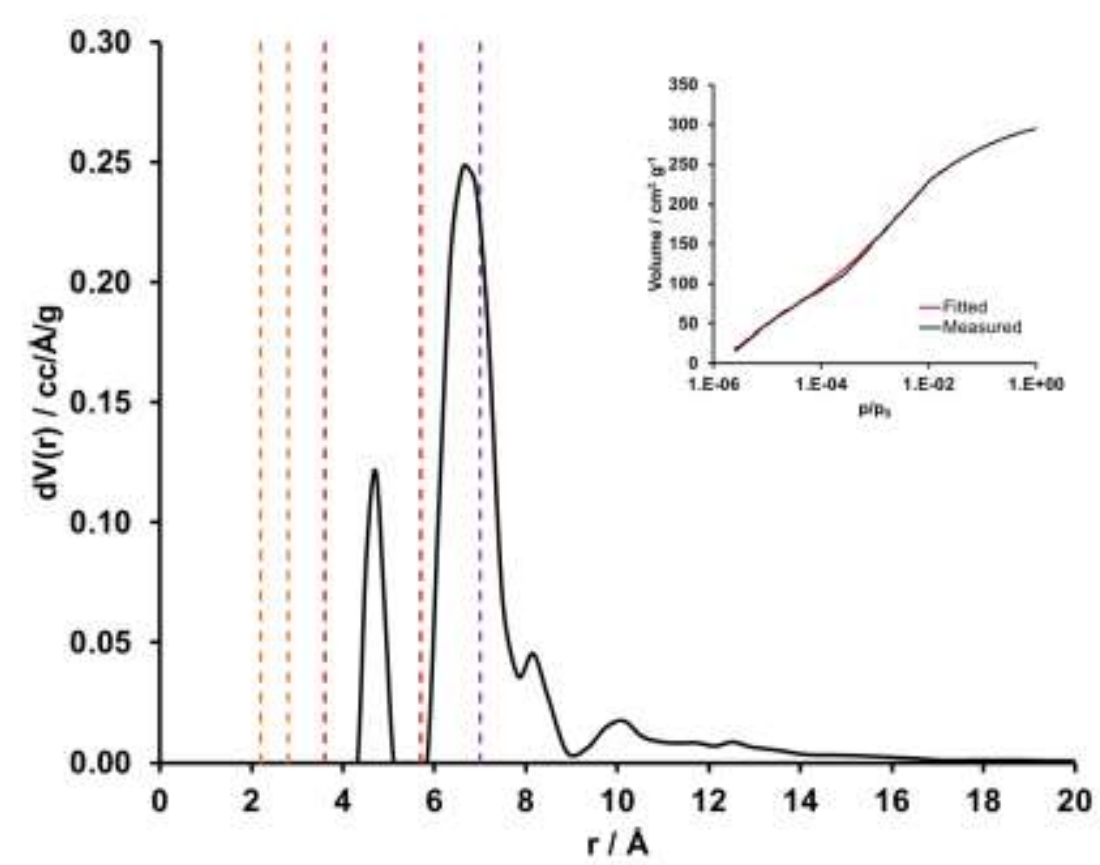

Figure S 10. DFT pore size distribution of DUT-67-Pa. The dotted lines correspond to the pore sizes calculated from Zeo ++ (yellow line: octahedral pore A, red line: cuboctahedral pore B with modulator, purple line: cuboctahedral pore $\mathrm{C}$ without modulator). In the right corner, the fit of the calculated and the measured isotherms is presented.

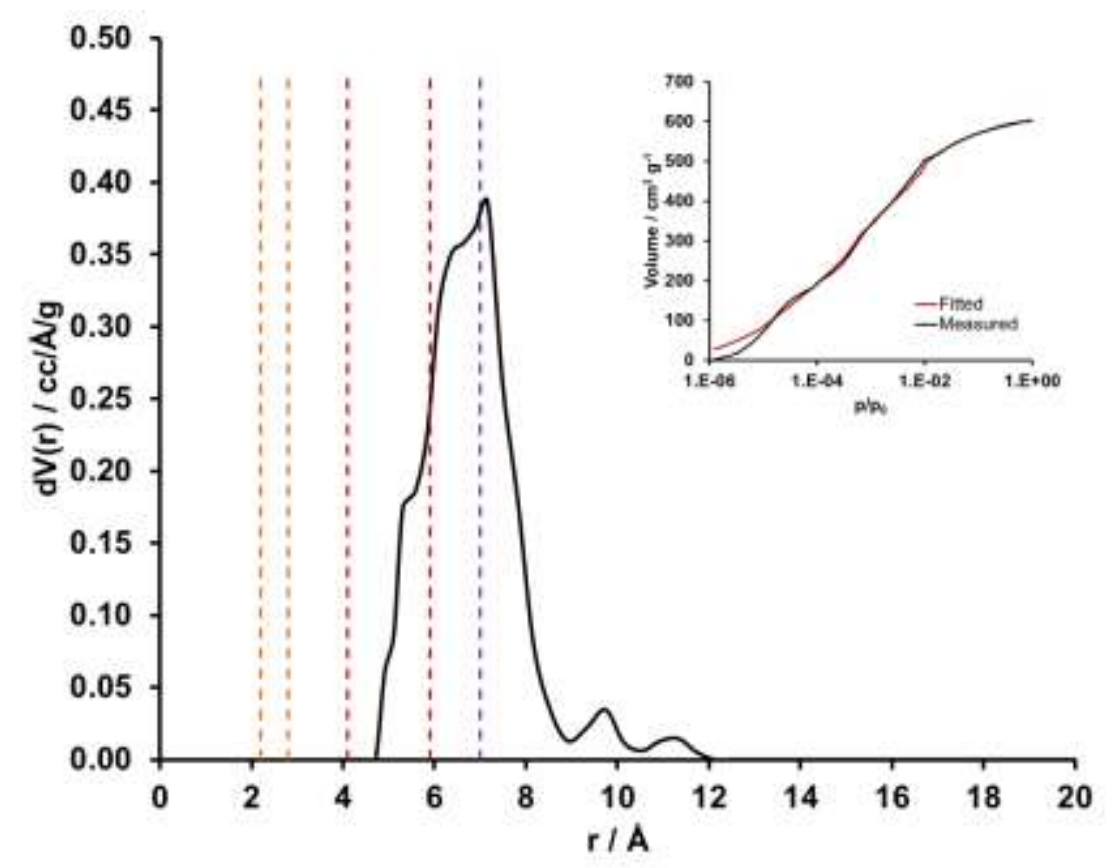

Figure S 11. DFT pore size distribution of DUT-67-Tfa. The dotted lines correspond to the pore sizes calculated from Zeo ++ (yellow line: octahedral pore A, red line: cuboctahedral pore B with modulator, purple line: cuboctahedral pore $\mathrm{C}$ without modulator). In the right corner, the fit of the calculated and the measured isotherms is presented. 


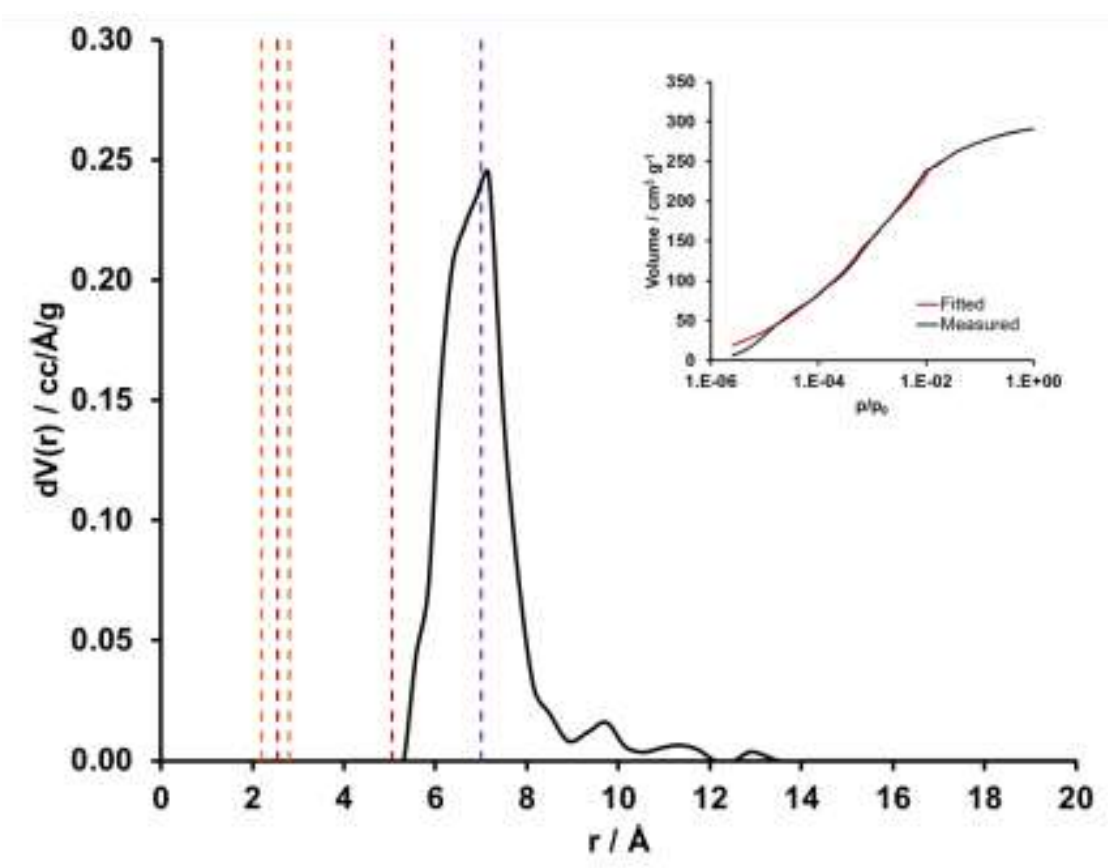

Figure S 12. DFT pore size distribution of DUT-67-Tfmba. The dotted lines correspond to the pore sizes calculated from Zeo ++ (yellow line: octahedral pore A, red line: cuboctahedral pore B with modulator, purple line: cuboctahedral pore $\mathrm{C}$ without modulator). In the right corner, the fit of the calculated and the measured isotherms is presented.

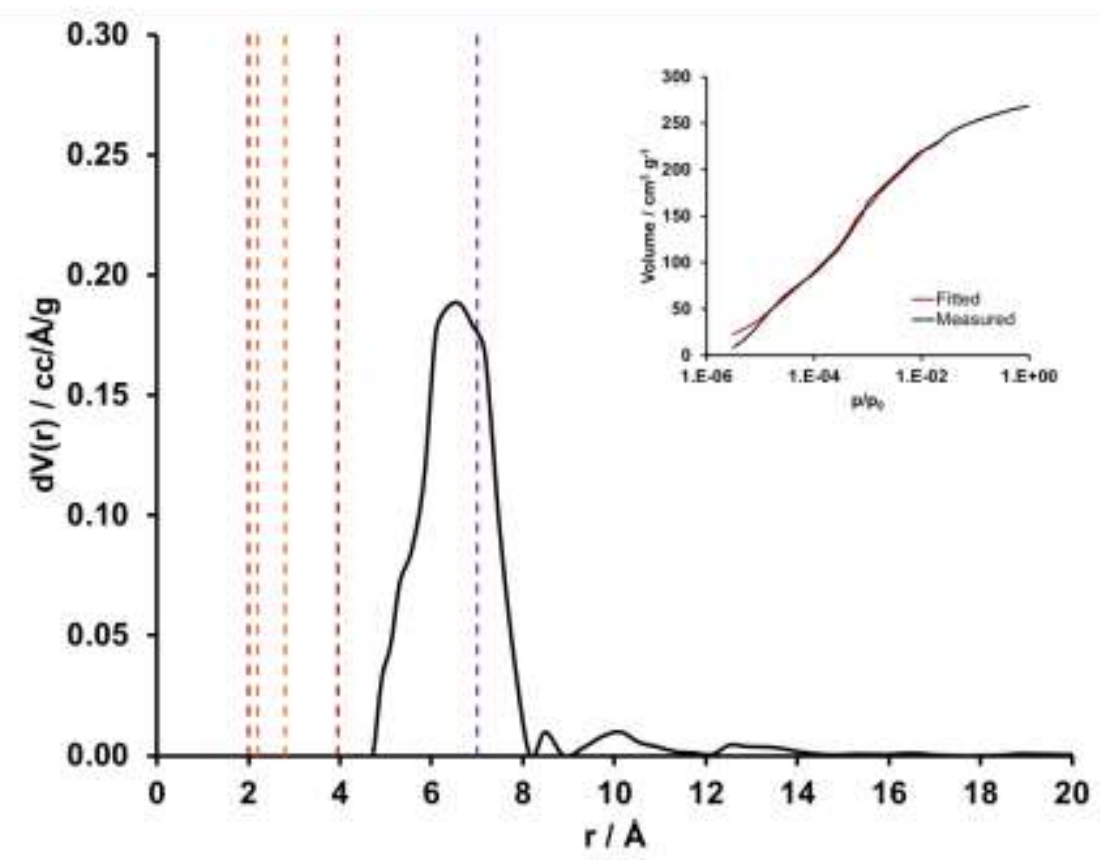

Figure S 13. DFT pore size distribution of DUT-67-Pfba. The dotted lines correspond to the pore sizes calculated from Zeo ++ (yellow line: octahedral pore A, red line: cuboctahedral pore B with modulator, purple line: cuboctahedral pore $\mathrm{C}$ without modulator). In the right corner, the fit of the calculated and the measured isotherms is presented. 


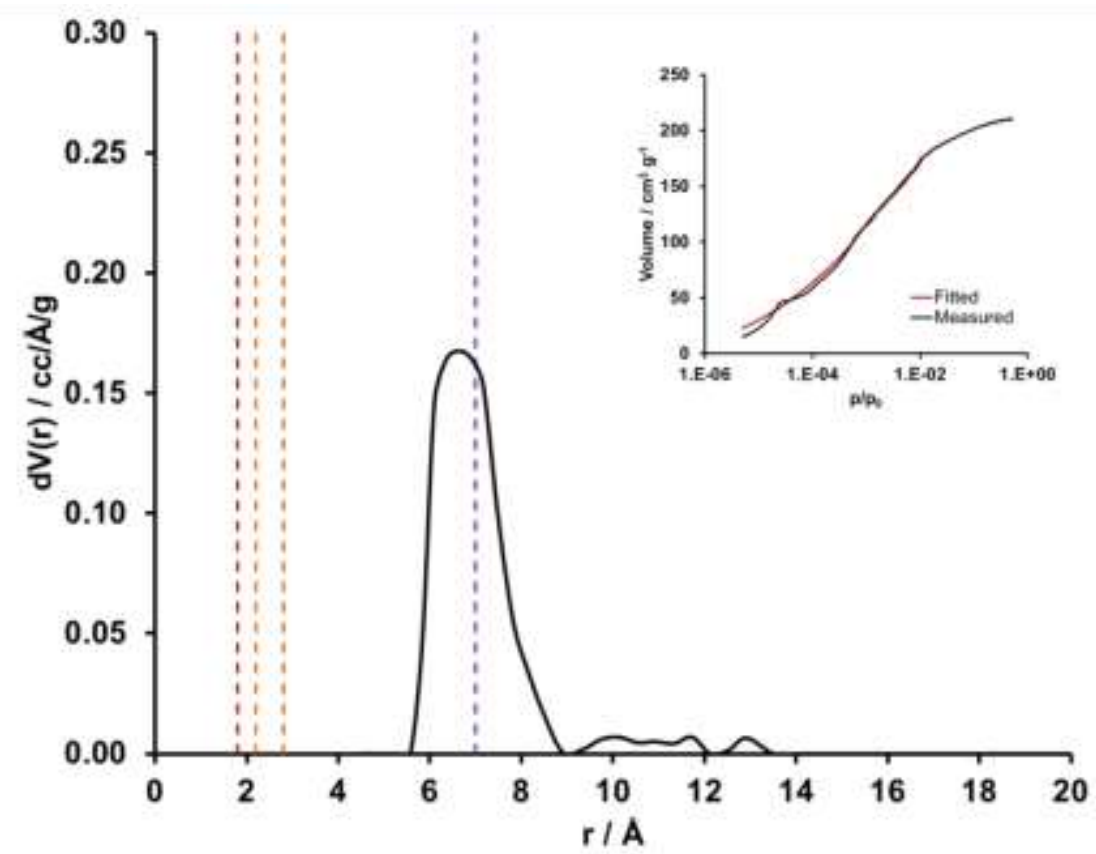

Figure S 14. DFT pore size distribution of DUT-67-Pfoa. The dotted lines correspond to the pore sizes calculated from Zeo ++ (yellow line: octahedral pore A, red line: cuboctahedral pore B with modulator, purple line: cuboctahedral pore $\mathrm{C}$ without modulator). In the right corner, the fit of the calculated and the measured isotherms is presented. 


\section{S.1.3 Water physisorption isotherms}

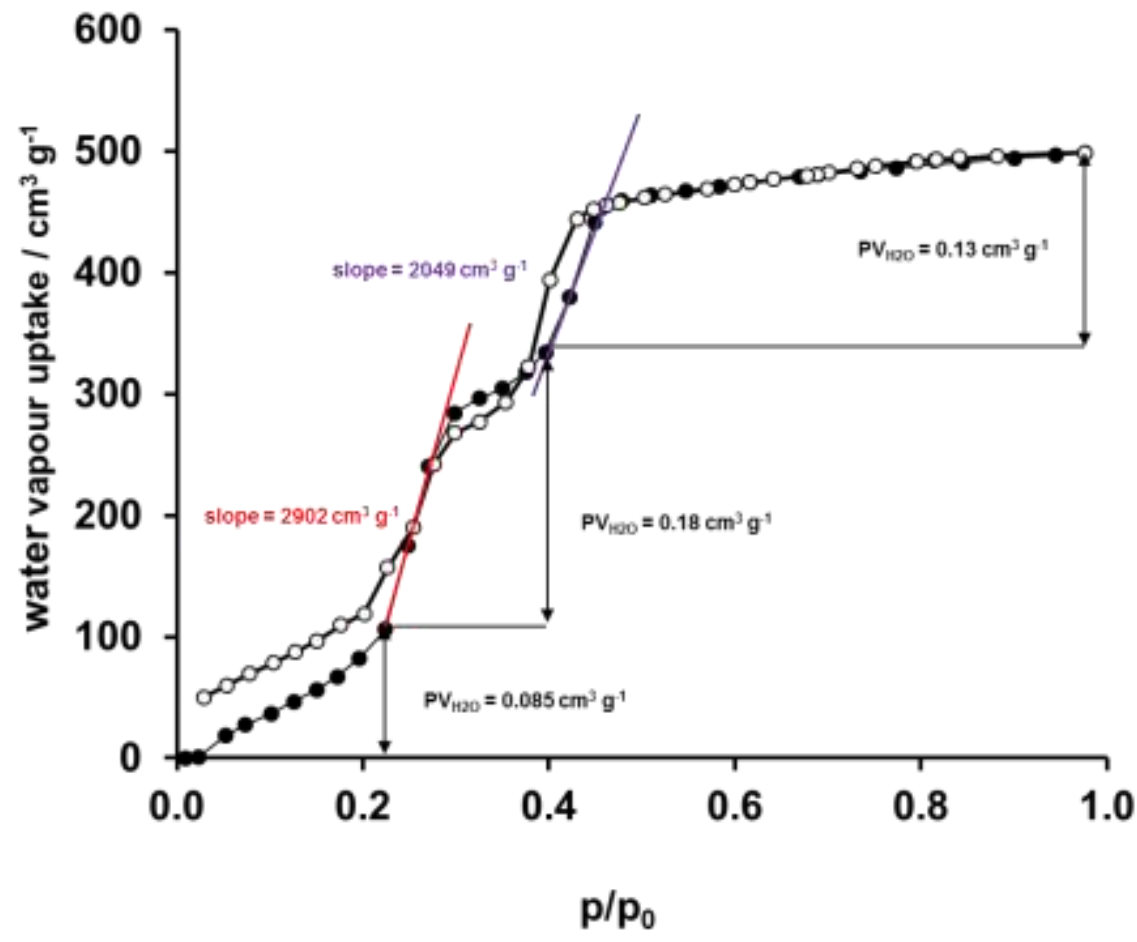

Figure S 15. Water adsorption (solid symbols) and desorption (blank symbols) isotherms at $298 \mathrm{~K}$ of DUT-67-Fa.

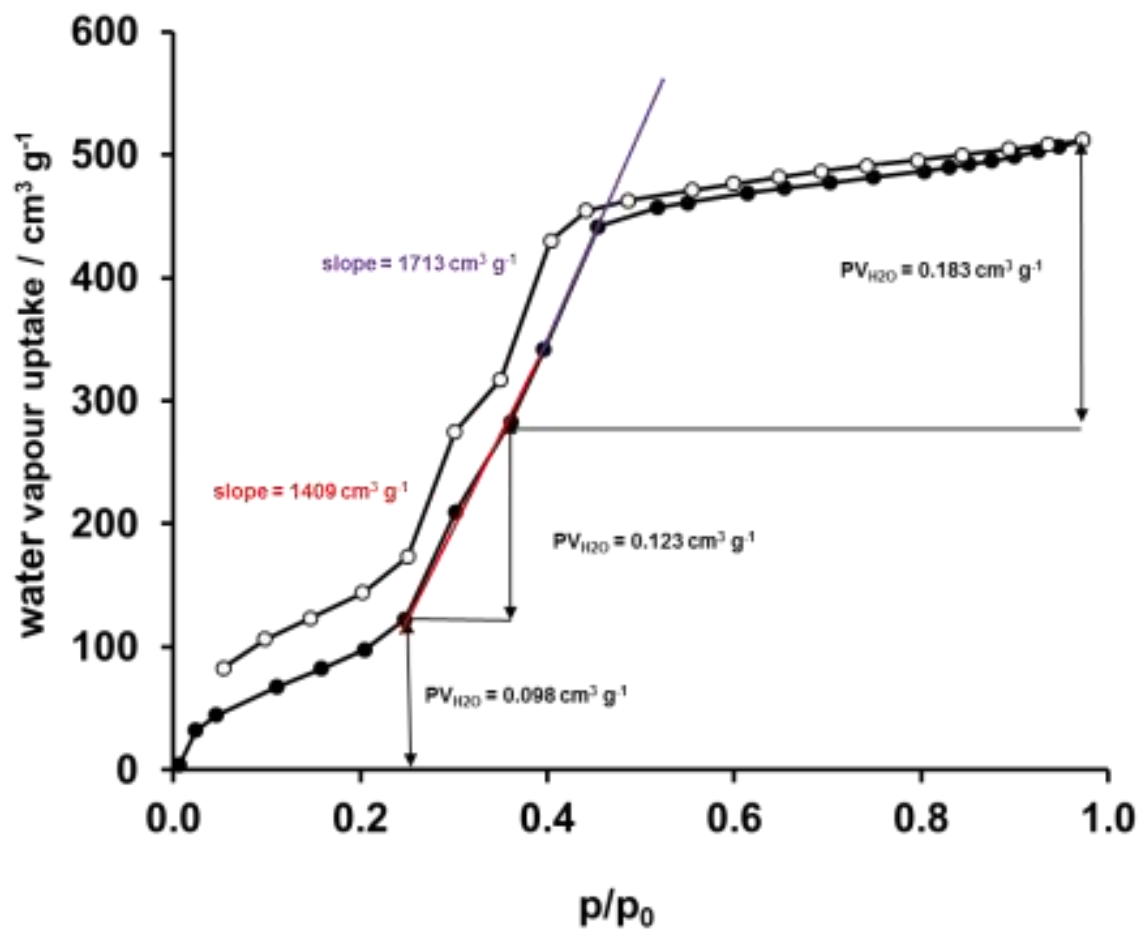

Figure S 16. Water adsorption (solid symbols) and desorption (blank symbols) isotherms at $298 \mathrm{~K}$ of DUT-67-Ac. 


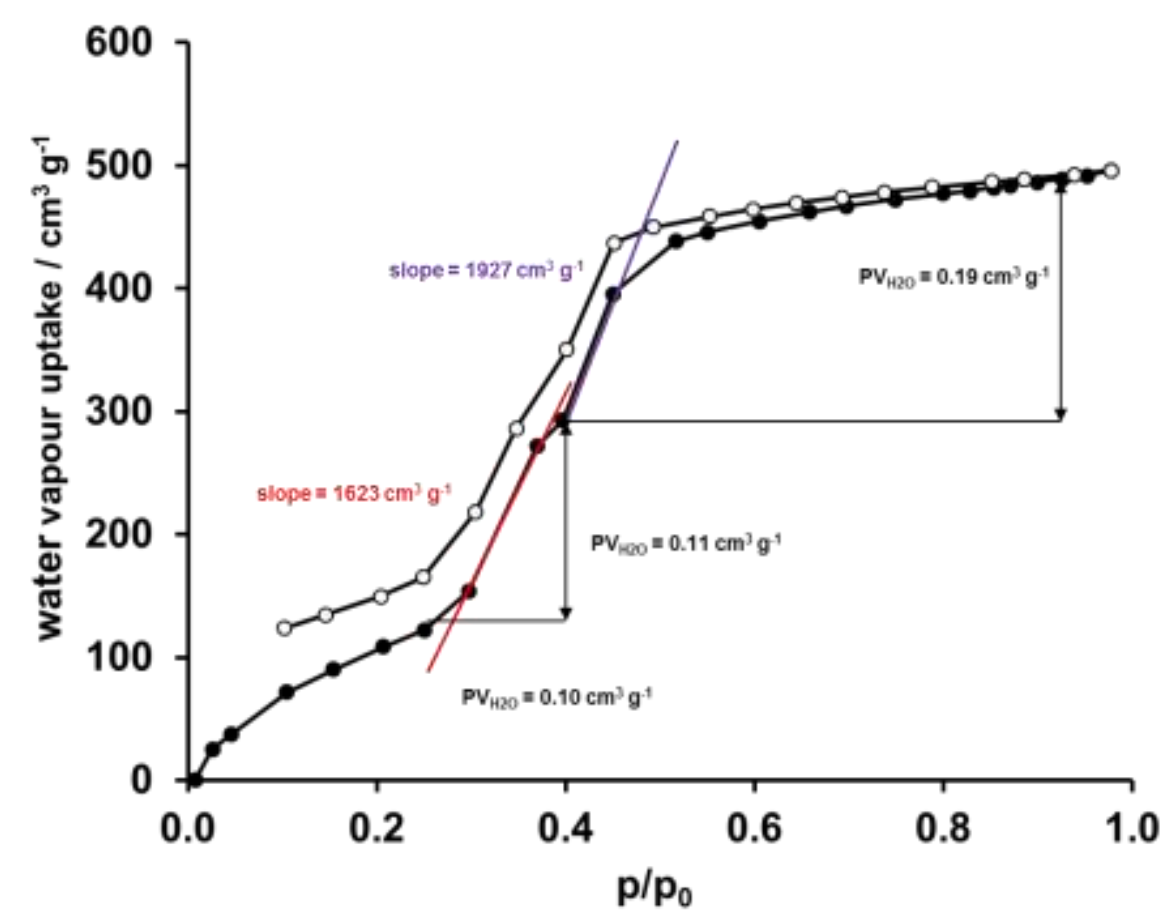

Figure S 17. Water adsorption (solid symbols) and desorption (blank symbols) isotherms at $298 \mathrm{~K}$ of DUT-67-Pa.

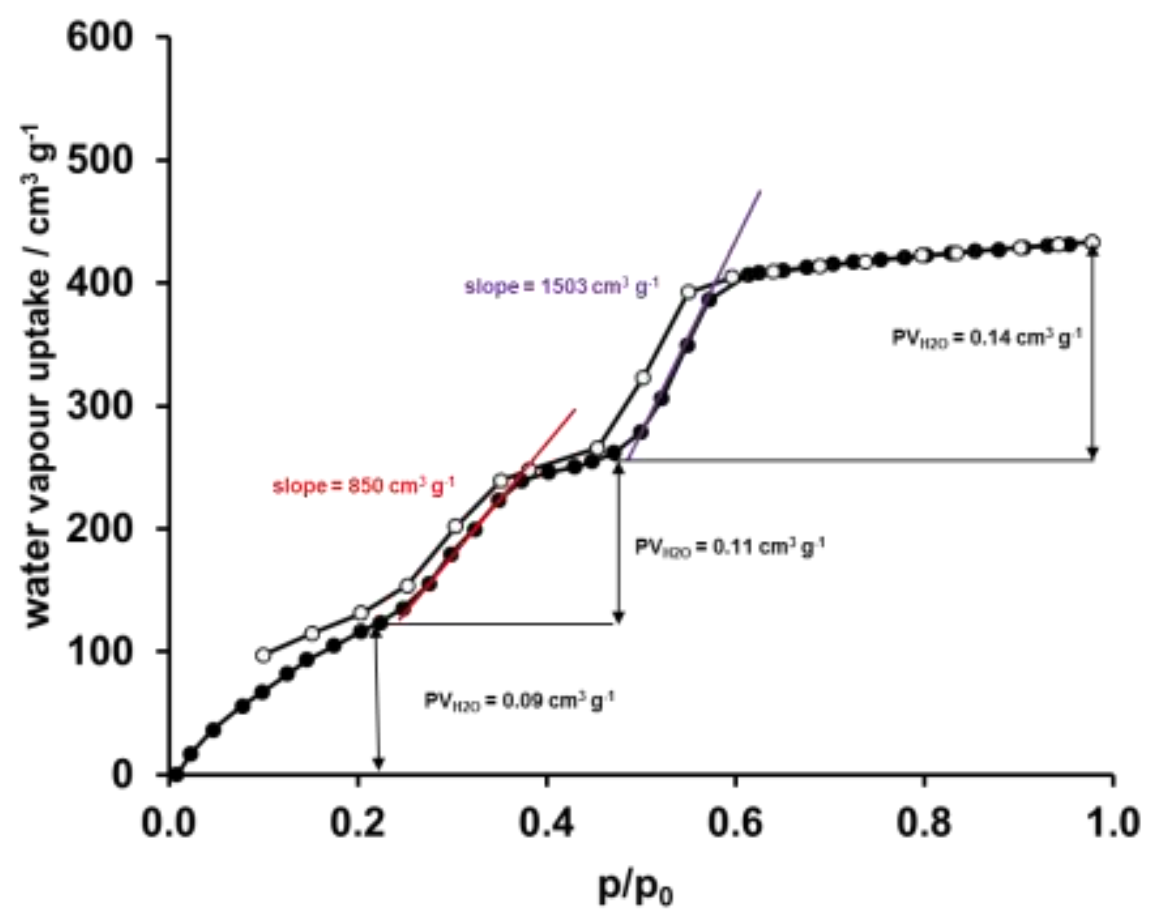

Figure S 18. Water adsorption (solid symbols) and desorption (blank symbols) isotherms at $298 \mathrm{~K}$ of DUT-67-Tfa. 


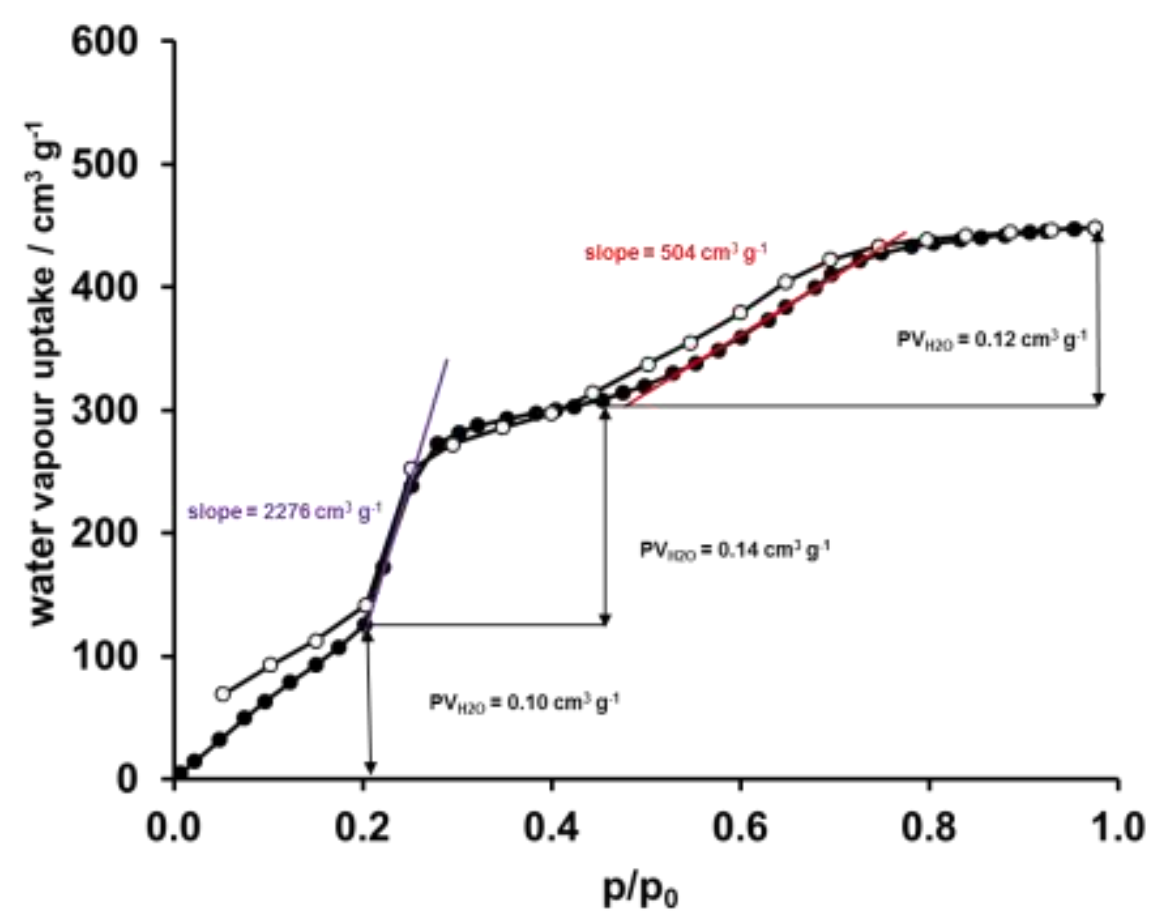

Figure S 19. Water adsorption (solid symbols) and desorption (blank symbols) isotherms at $298 \mathrm{~K}$ of DUT-67-Tfmba.

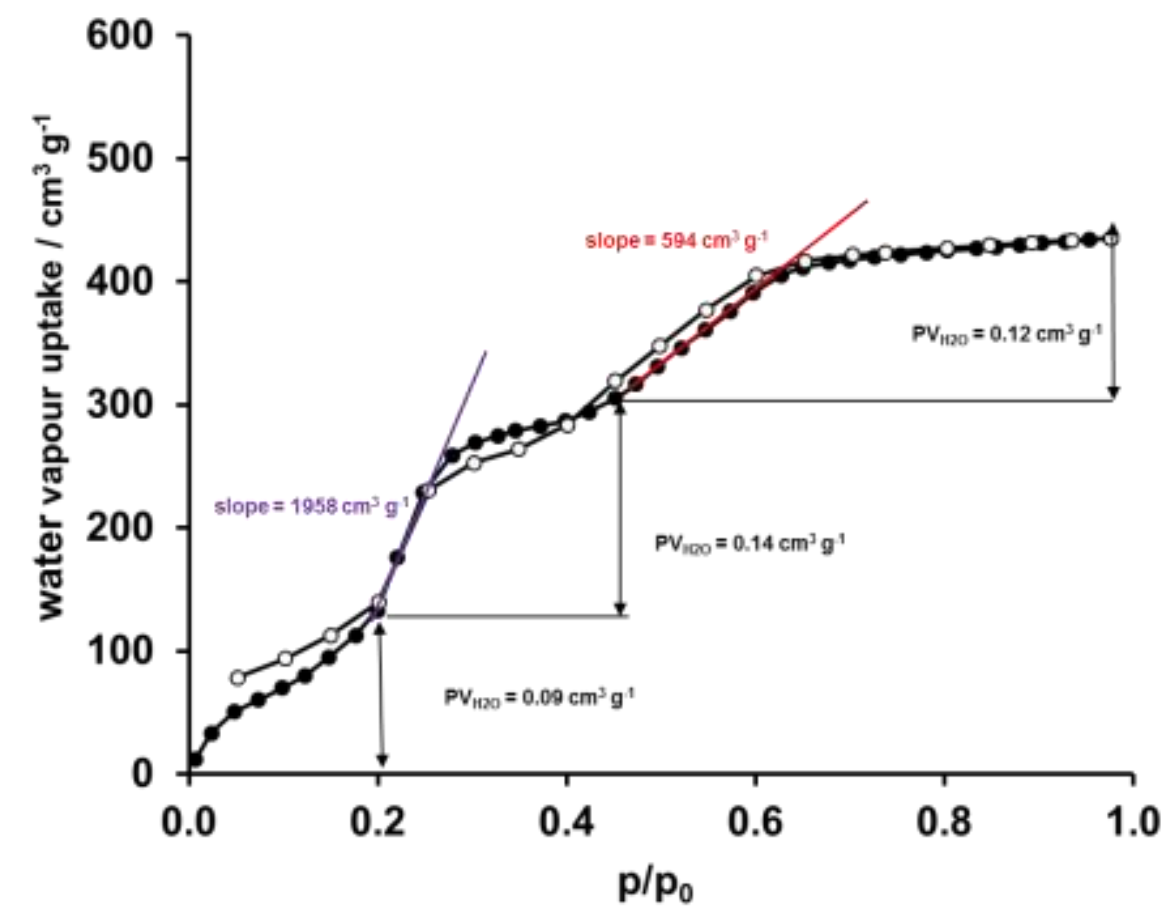

Figure S 20. Water adsorption (solid symbols) and desorption (blank symbols) isotherms at $298 \mathrm{~K}$ of DUT-67-Pfba. 


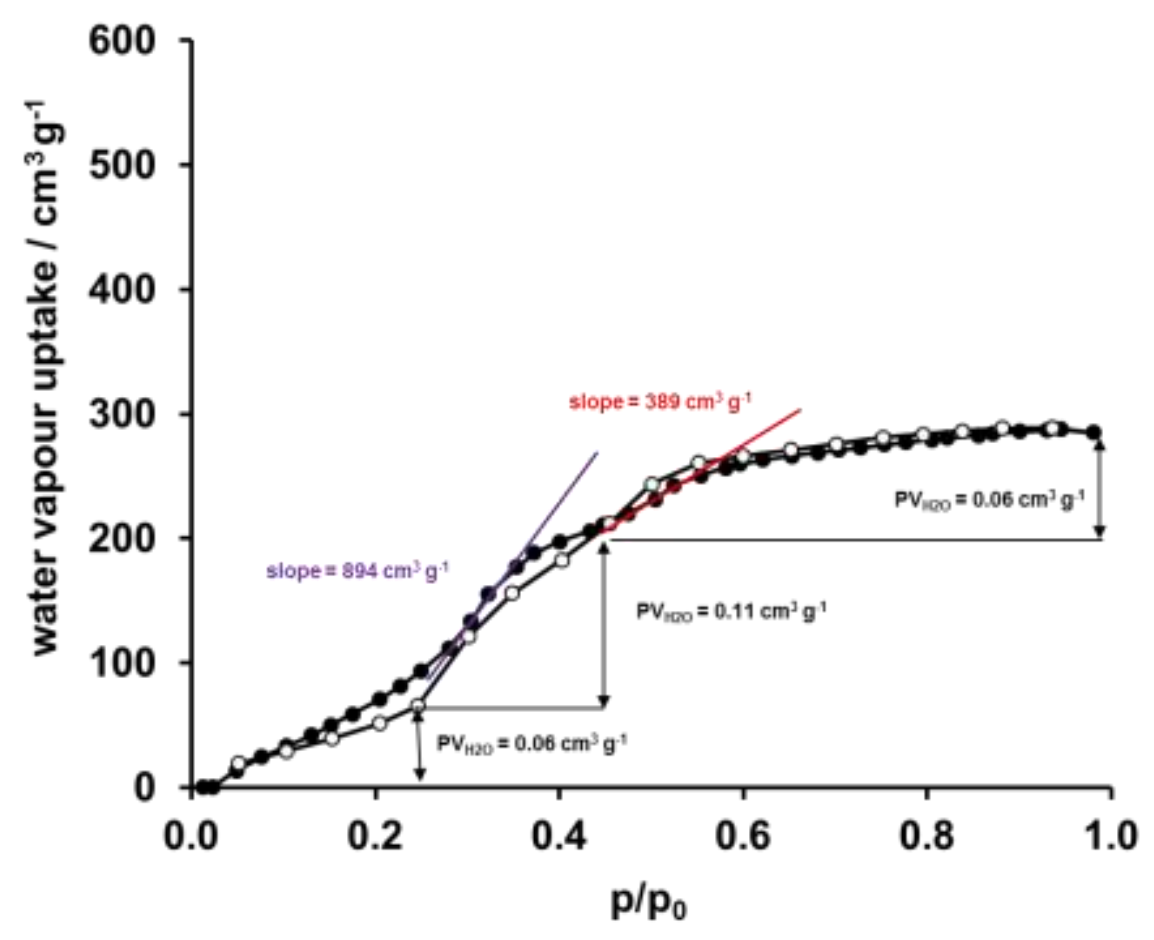

Figure S 21. Water adsorption (solid symbols) and desorption (blank symbols) isotherms at $298 \mathrm{~K}$ of DUT-67-Pfoa. 


\section{S2. Powder X-ray data}

The theoretical PXRD pattern of DUT-67 was calculated from the single crystal X-ray structure.

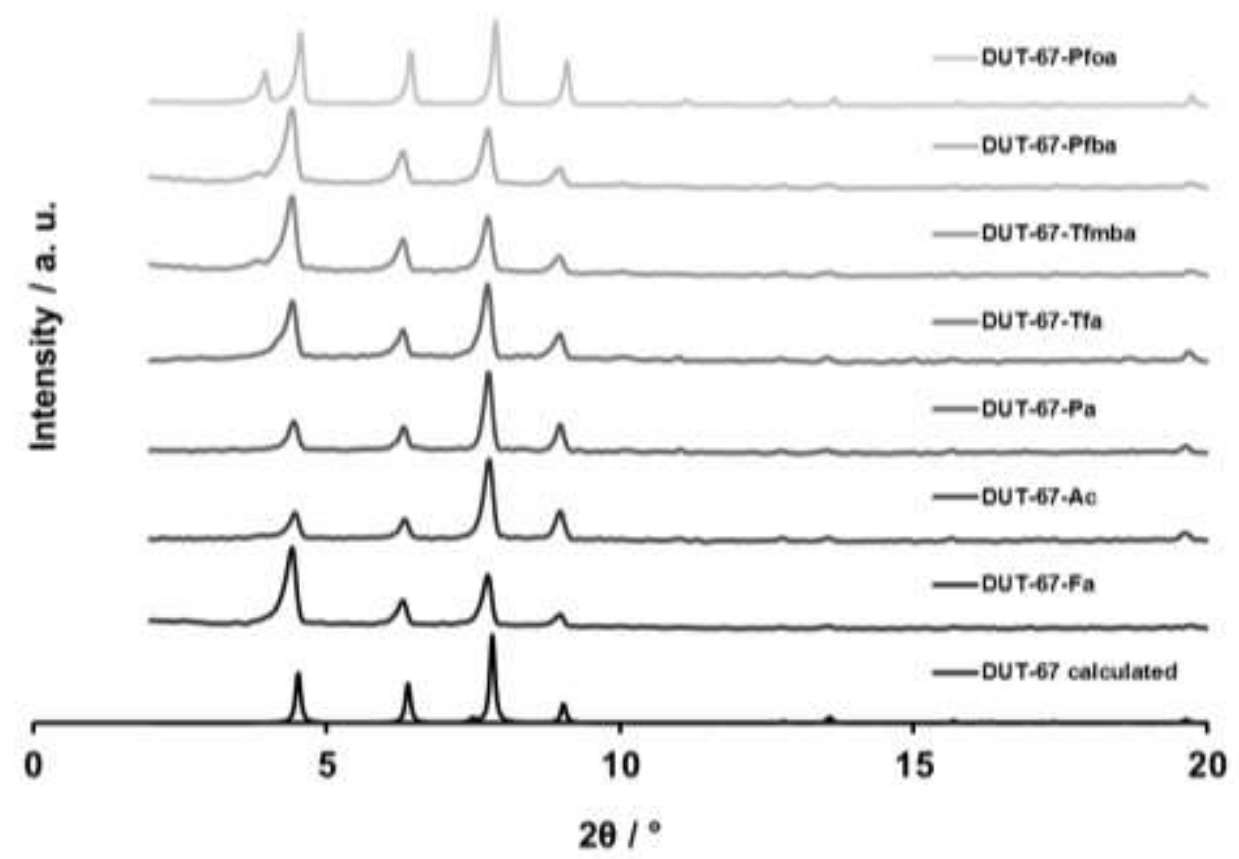

Figure S 22. PXRD patterns of as made DUT-67-Fa, DUT-67-Ac, DUT-67-Pa and PXRD patterns of DUT-67-Tfa, DUT-67-Tfmba, DUT-67-Pfba, and DUT-67-Pfoa activated at $100{ }^{\circ} \mathrm{C}$ in vacuum.

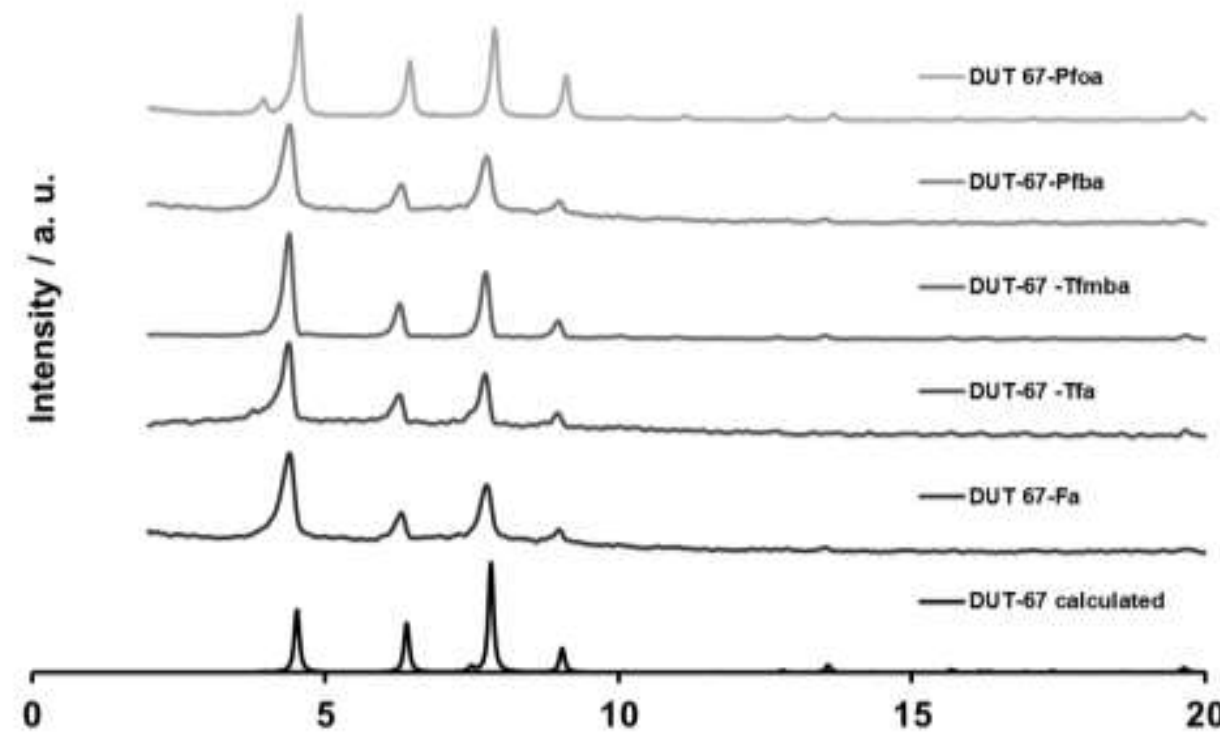

$2 \theta /^{\circ}$

Figure S 23. PXRD patterns of DUT-67 after water desorption and activation in vacuum at 100 ${ }^{\circ} \mathrm{C}$. 


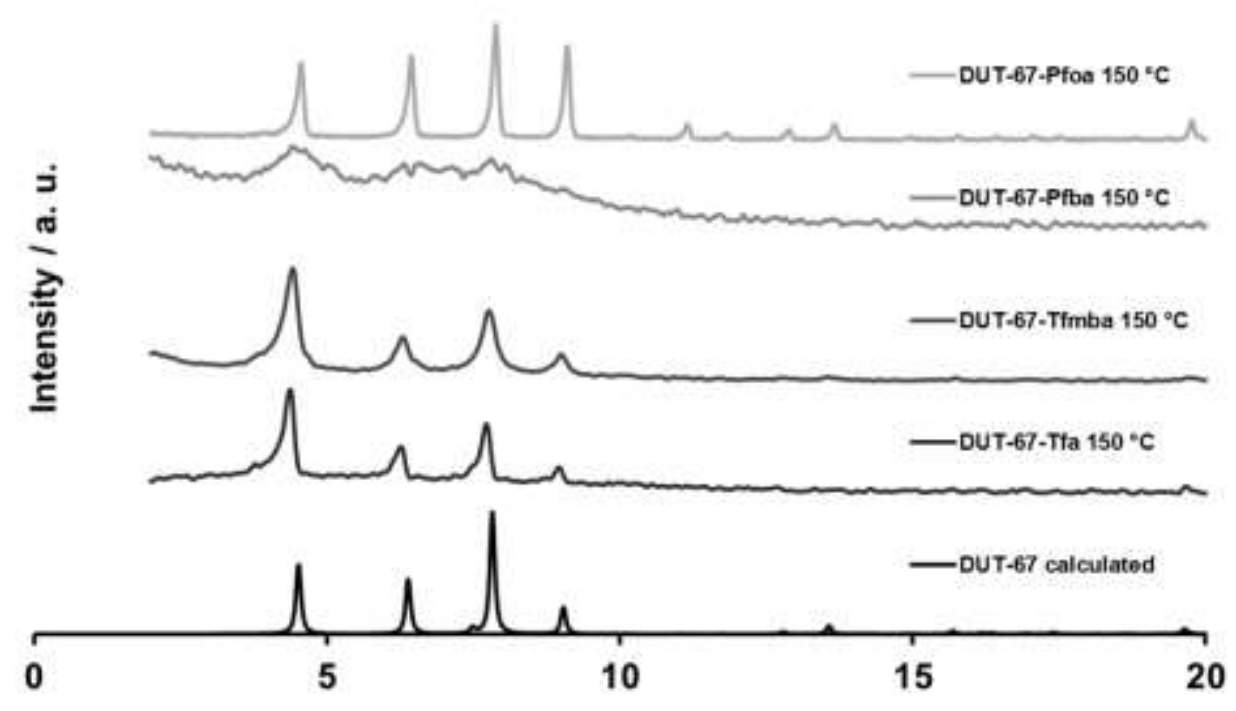

$2 \theta 1^{\circ}$

Figure S 24. PXRD patterns of DUT-67 after activation in vacuum at $150{ }^{\circ} \mathrm{C}$.

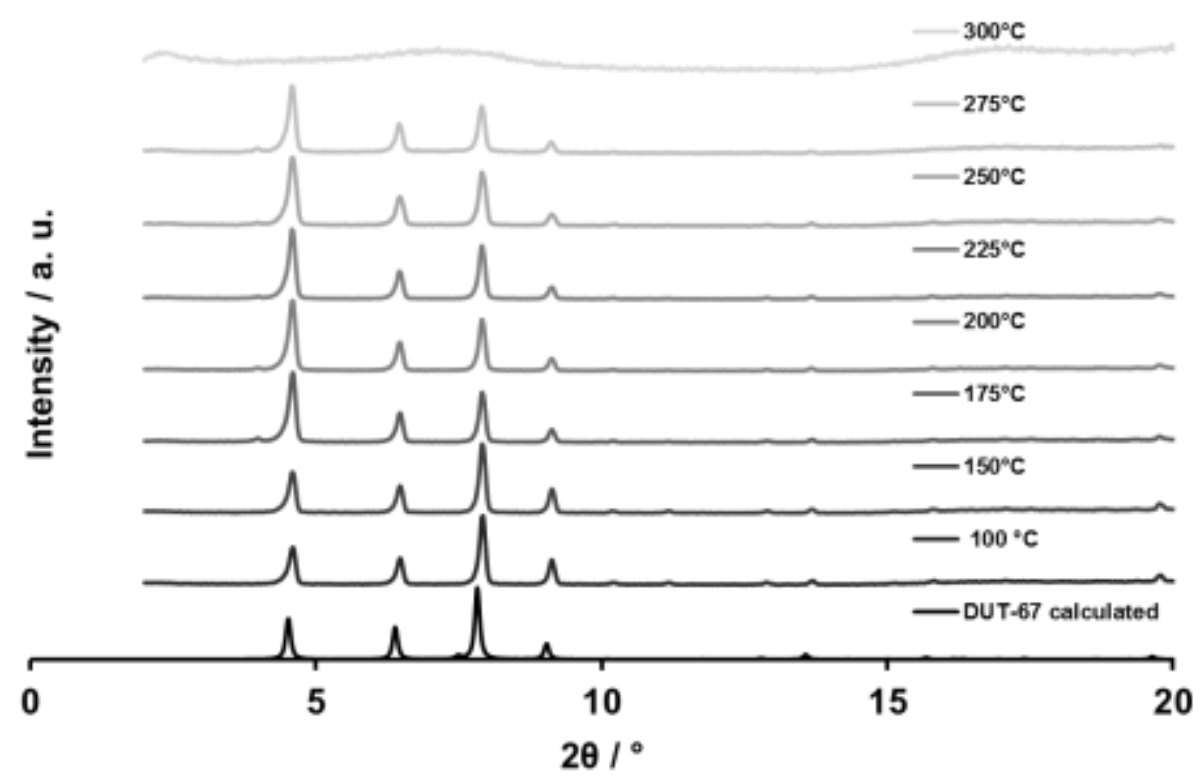

Figure S 25. Thermo-PXRD patterns of DUT-67-Fa at different temperatures $\left(100{ }^{\circ} \mathrm{C}-300{ }^{\circ} \mathrm{C}\right)$ in air atmosphere. 
Section S3. Thermogravimetric analysis (TGA) and differential thermal analysis (TGA)

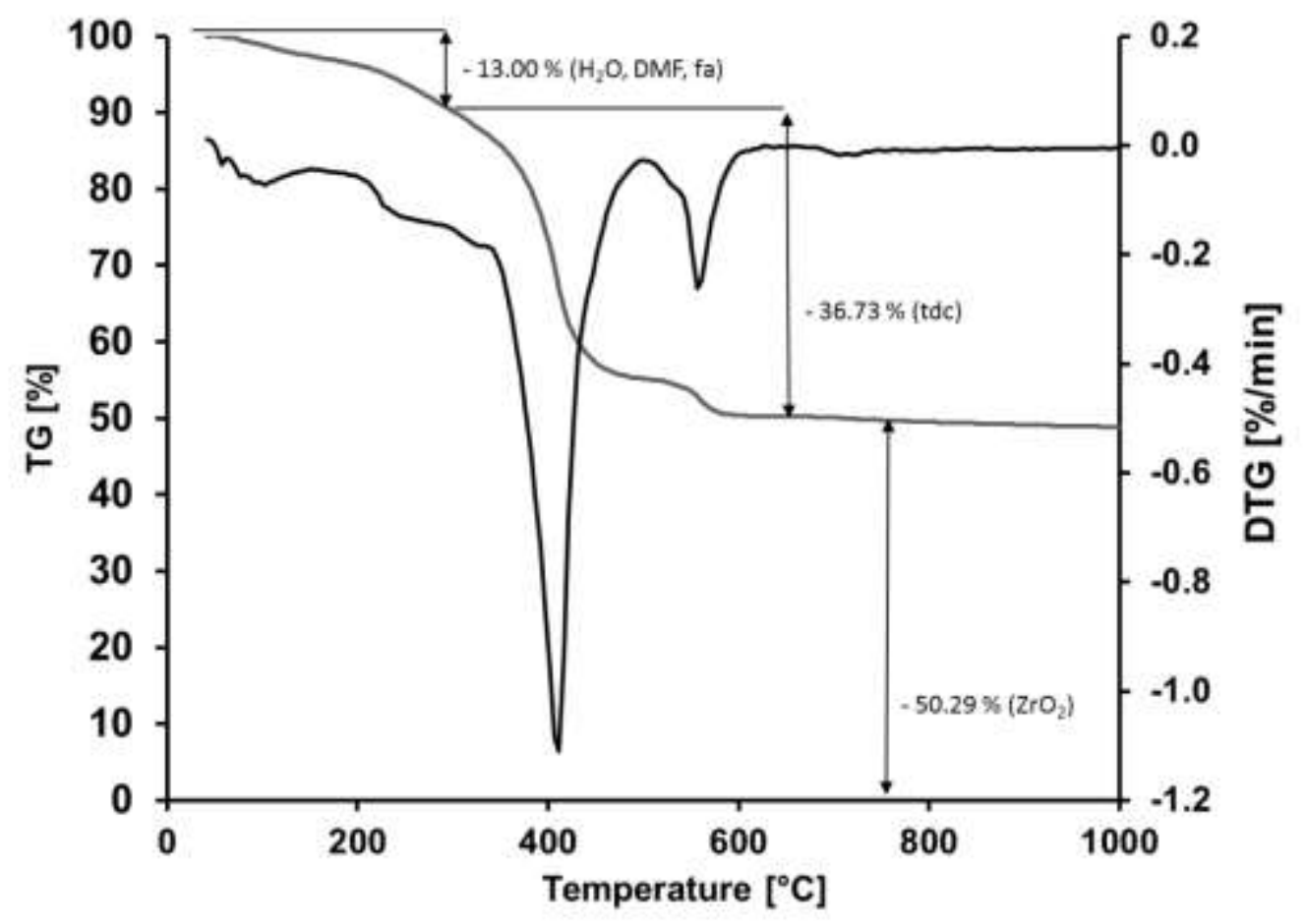

Figure S 26. TGA (grey line) and DTA (black line) of DUT-67-Fa activated at $120^{\circ} \mathrm{C}$.

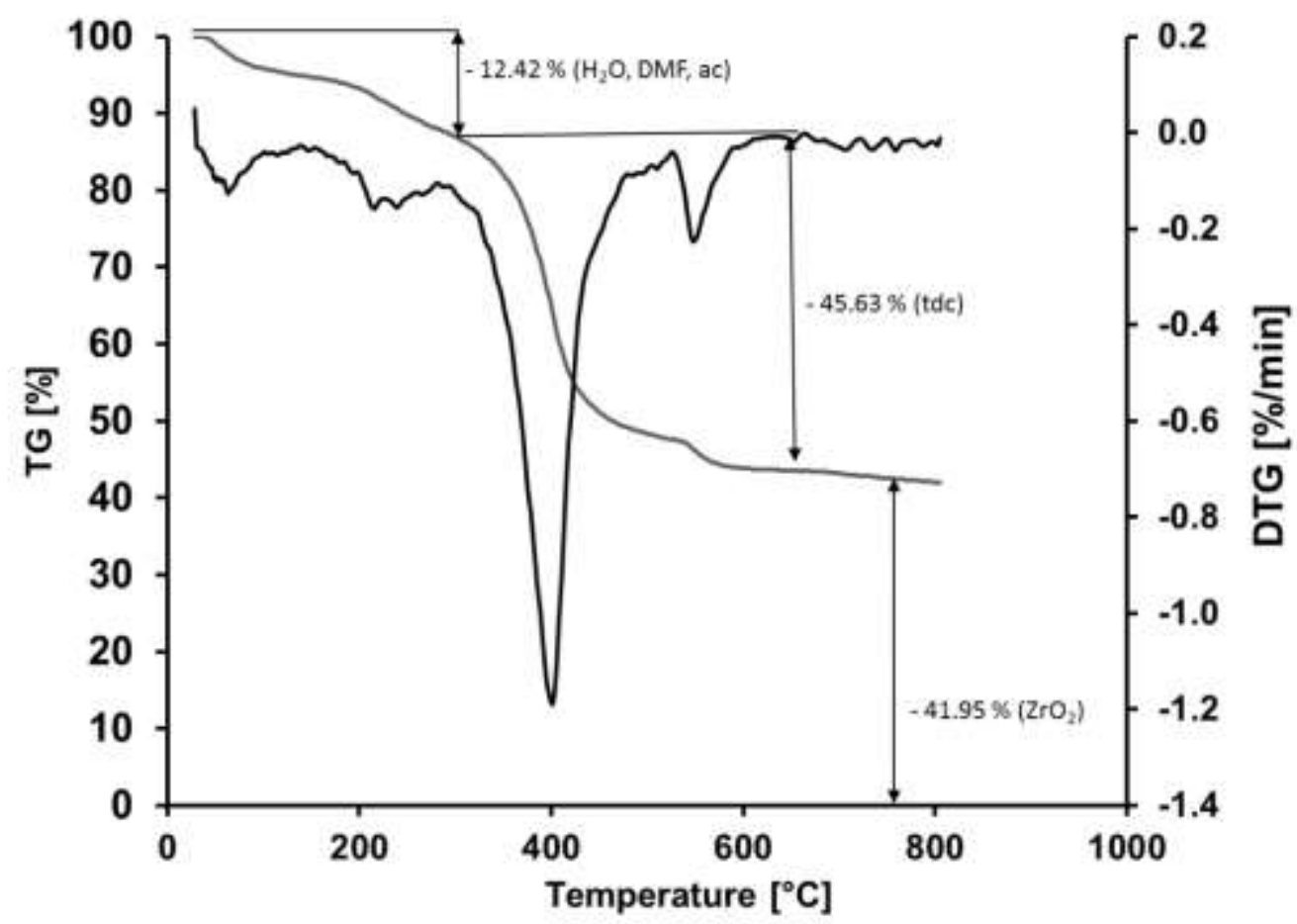

Figure S 27. TGA (grey line) and DTA (black line) of DUT-67-Ac activated at $120^{\circ} \mathrm{C}$. 


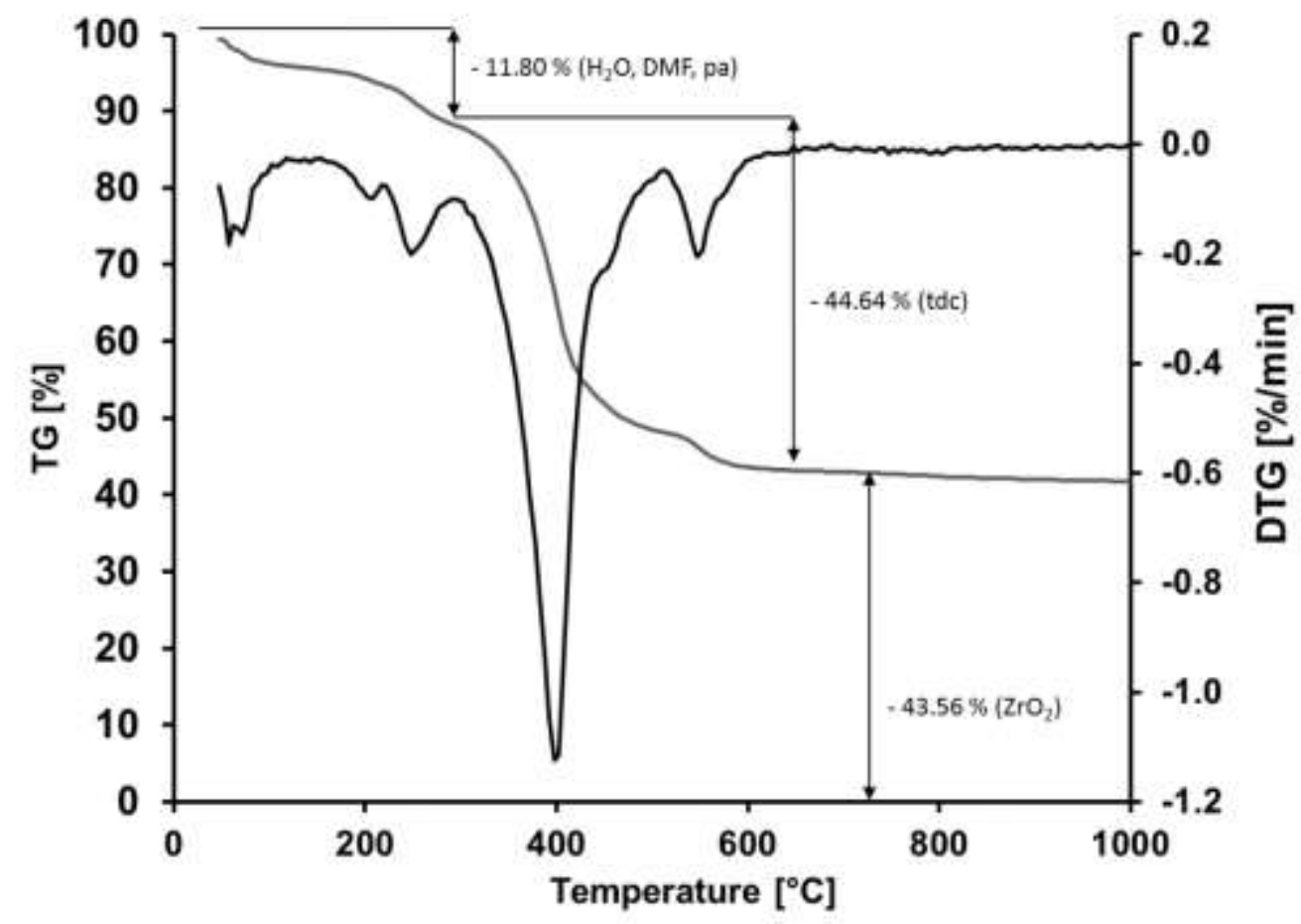

Figure S 28. TGA (grey line) and DTA (black line) of DUT-67-Pa activated at $120{ }^{\circ} \mathrm{C}$.

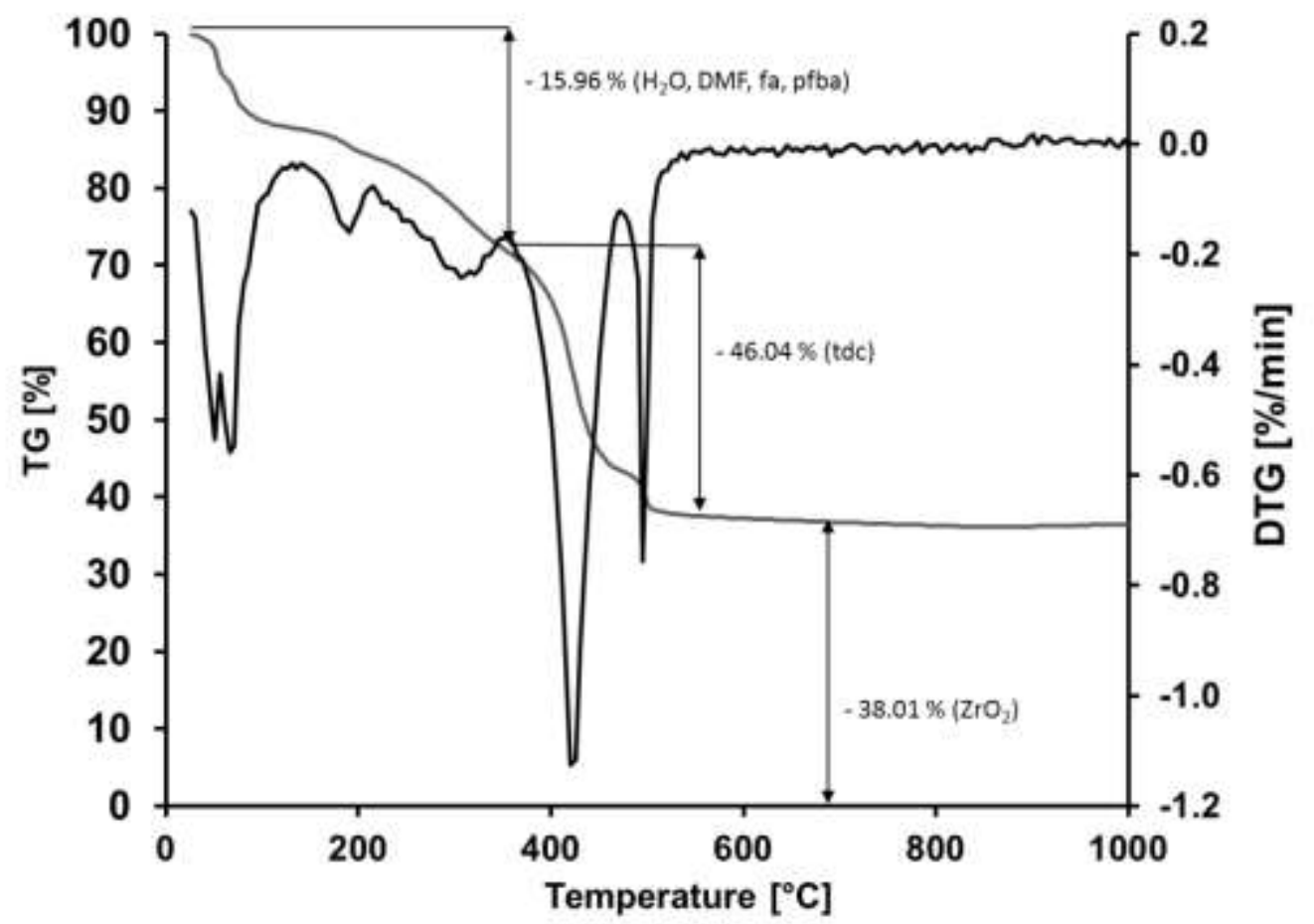

Figure S 29. TGA (grey line) and DTA (black line) of DUT-67-Pfba activated at $100{ }^{\circ} \mathrm{C}$. 


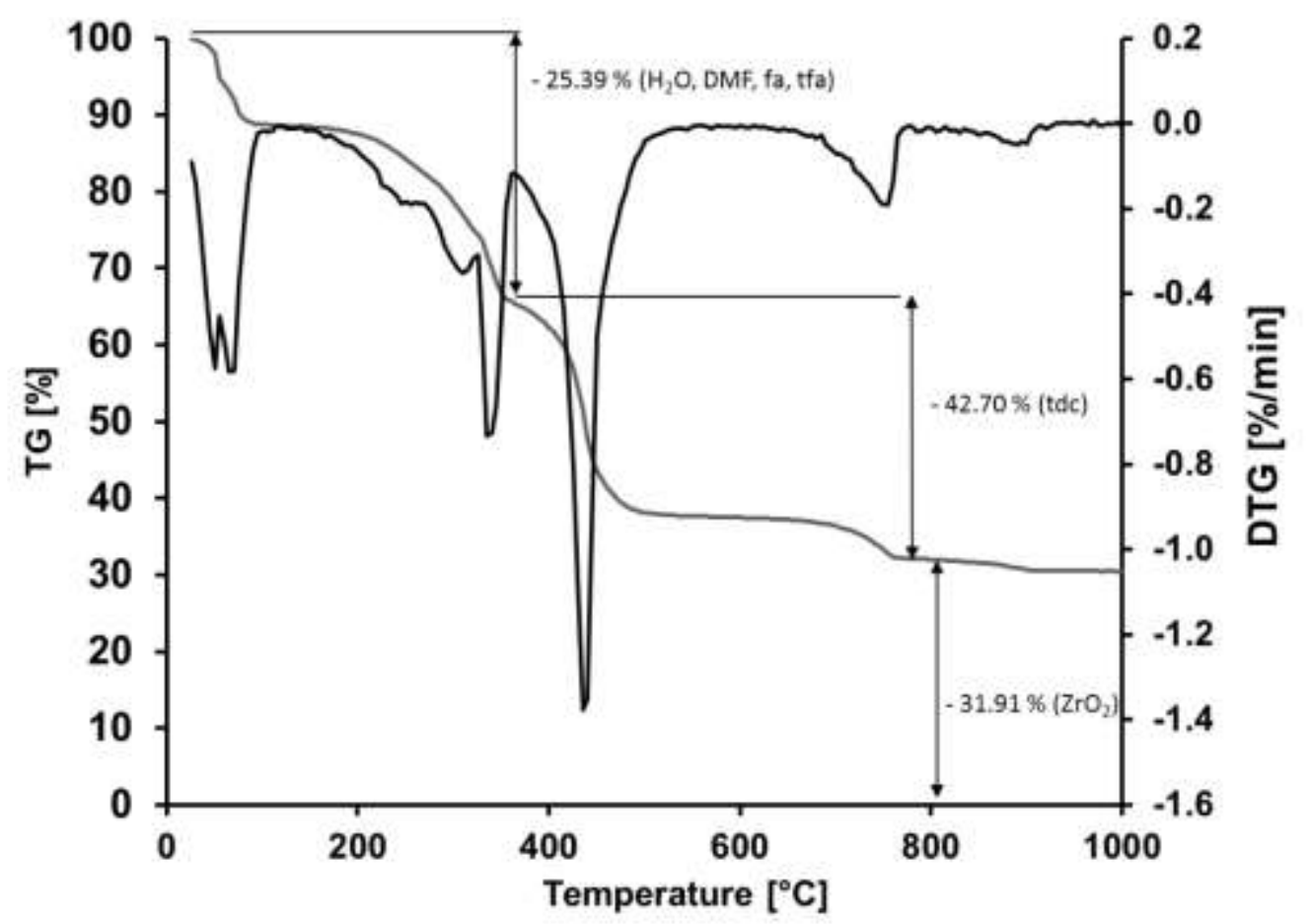

Figure S 30. TGA (grey line) and DTA (black line) of DUT-67-Tfa activated at $100{ }^{\circ} \mathrm{C}$.

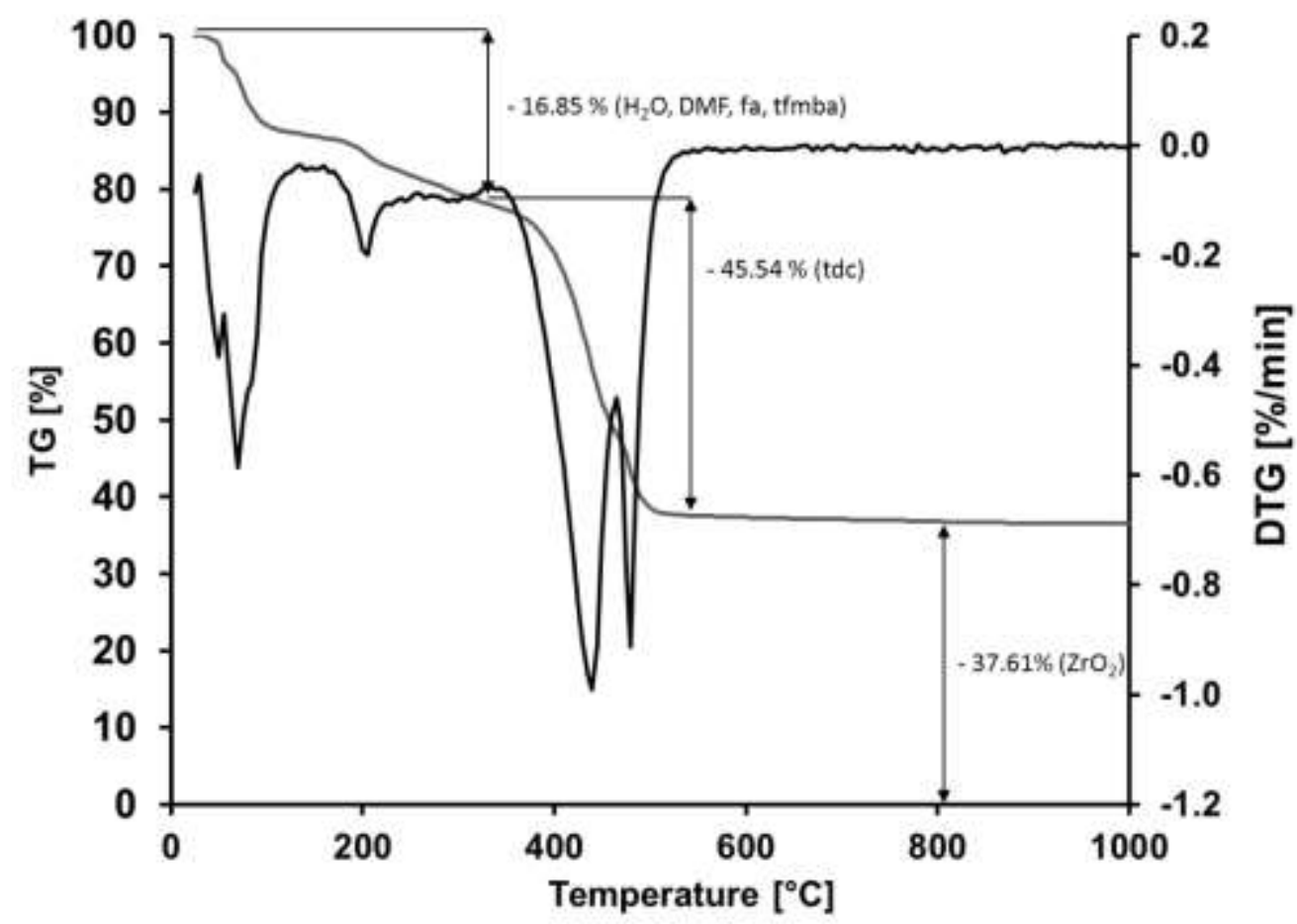

Figure S 31. TG analysis (grey line) and DTA analysis (black line) of DUT-67-Tfmba activated at $100{ }^{\circ} \mathrm{C}$. 


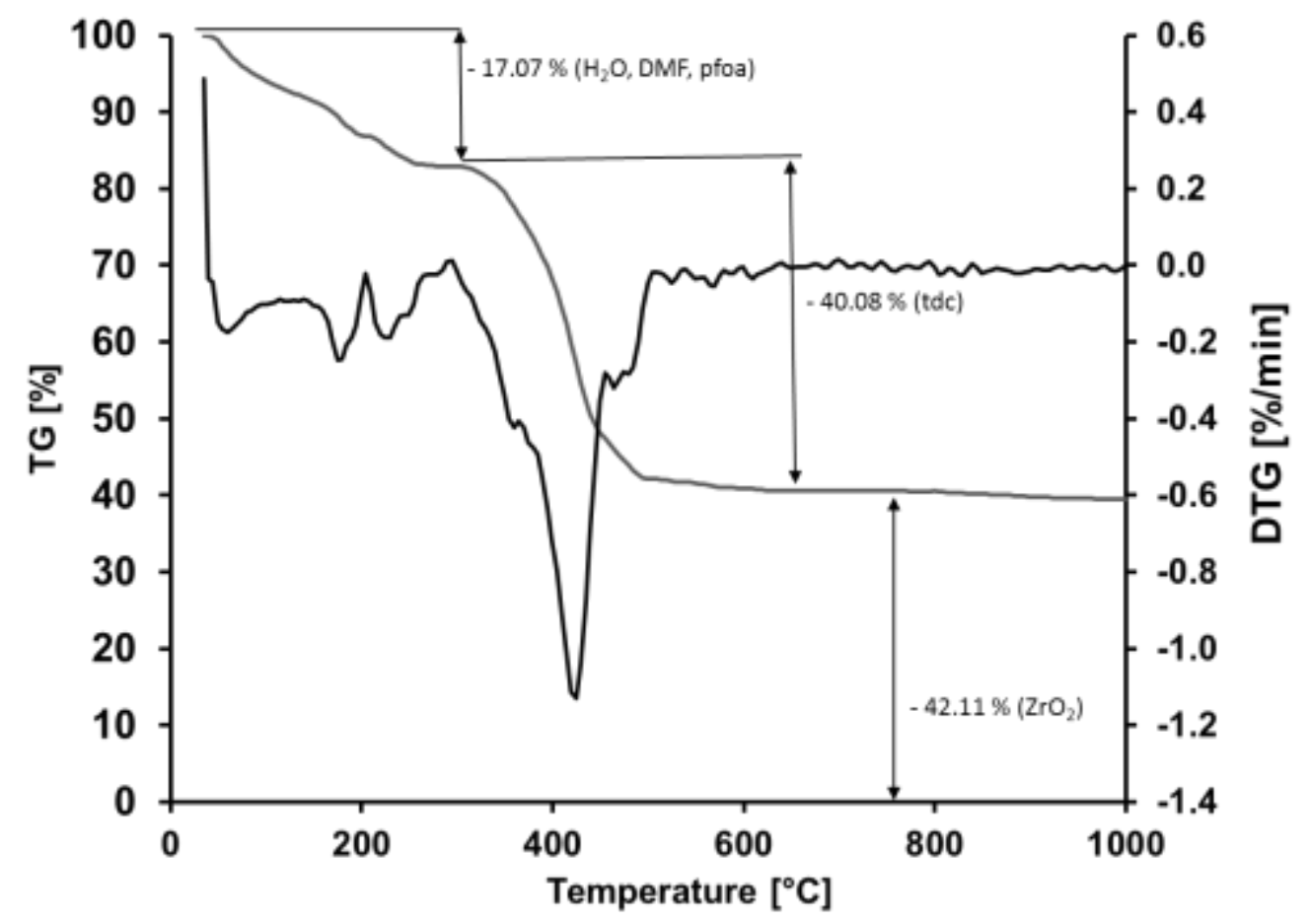

Figure S 32. TG analysis (grey line) and DTA analysis (black line) of DUT-67-Pfoa activated at $100{ }^{\circ} \mathrm{C}$.

Table S1. Monocarboxylic ligand release temperature.

\begin{tabular}{|c|c|c|}
\hline Modulator & pKa & $\begin{array}{l}\text { Temperature } \\
\text { of modulator } \\
\text { loss according } \\
\text { to TGA } /{ }^{\circ} \mathrm{C}\end{array}$ \\
\hline Propionic acid (HPa) & 4.87 & 239 \\
\hline Acetic acid (HAc) & 4.76 & 236 \\
\hline Formic acid (HFa) & 3.75 & 217 \\
\hline Trifluoromethylbenzoic acid (HTfmba) & 3.6 & 200 \\
\hline Pentafluorobenzoic acid (HPfba) & 1.6 & 190 \\
\hline Trifluoroacetic acid $(\mathrm{Tfa})^{*}$ & 0.23 & $190-335$ \\
\hline Perfluorooctanoic acid (HPfoa) & 0 & 174 \\
\hline
\end{tabular}




\section{S4 NMR data}

S4.1: ${ }^{1} \mathrm{H}-\mathrm{NMR}$ data of the as synthesized DUT-67-Fa and DUT-67-Pa as well as the DUT-67 with the exchanged fluorinated modulators.

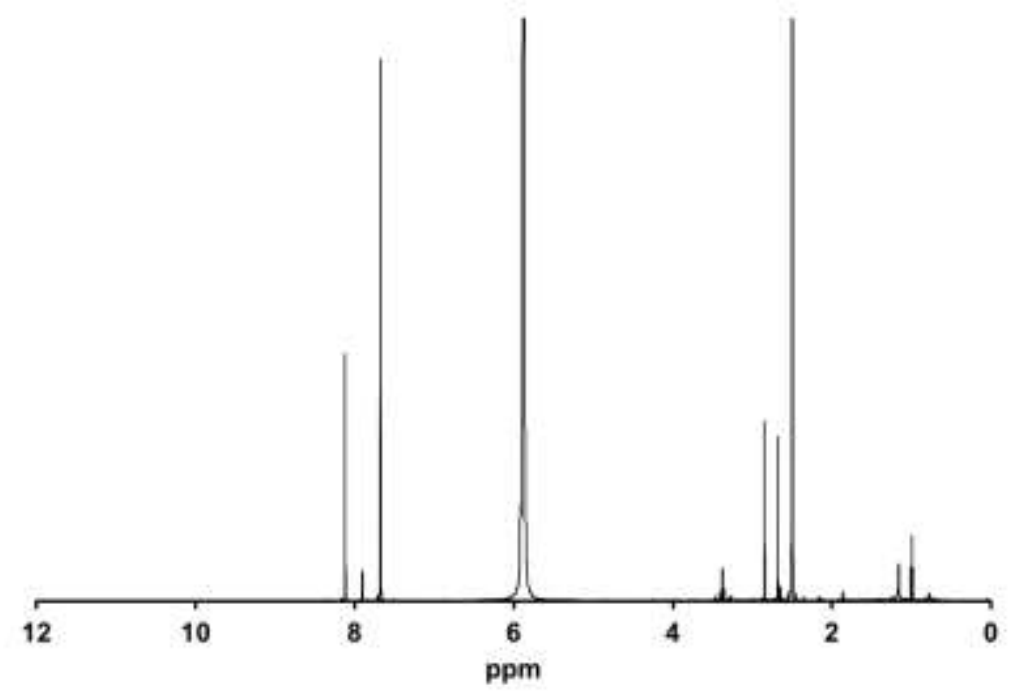

Figure S 33. ${ }^{1} \mathrm{H}-\mathrm{NMR}$ data of DUT-67-Fa.

${ }^{1} \mathrm{H}-\mathrm{NMR}:(\mathrm{DMSO} / \mathrm{DCl}): \delta / \mathrm{ppm}=8.12(\mathrm{~s}, 1 \mathrm{H}, \mathrm{fa}), \delta / \mathrm{ppm}=7.68(\mathrm{~s}, 2 \mathrm{H}, \mathrm{tdc}), \delta / \mathrm{ppm}=2.85$, $2.68(\mathrm{~s}, 3 \mathrm{H}, \mathrm{DMF}), \delta / \mathrm{ppm}=7.9(\mathrm{~s}, 1 \mathrm{H}, \mathrm{DMF}), \delta / \mathrm{ppm}=0.99(\mathrm{t}, 3 \mathrm{H}, \mathrm{EtOH}), \delta / \mathrm{ppm}=3.38(\mathrm{q}$, $2 \mathrm{H}, \mathrm{EtOH})$.

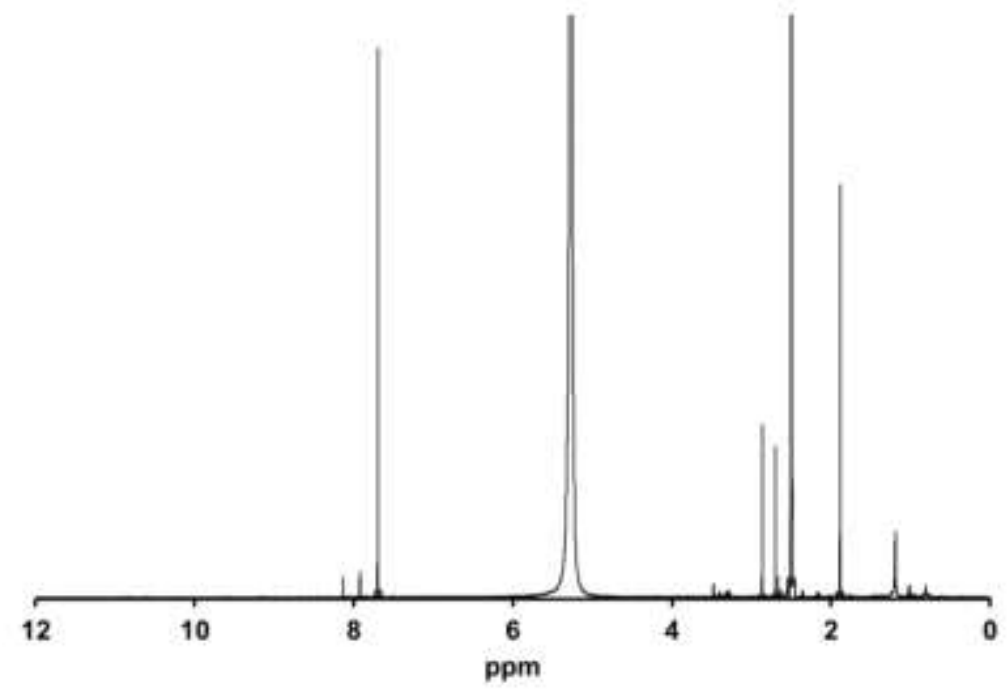

Figure S 34. ${ }^{1} \mathrm{H}-\mathrm{NMR}$ data of DUT-67-Ac.

${ }^{1} \mathrm{H}-\mathrm{NMR}:(\mathrm{DMSO} / \mathrm{DCl}): \delta / \mathrm{ppm}=1.89(\mathrm{~s}, 3 \mathrm{H}, \mathrm{ac}), \delta / \mathrm{ppm}=7.70(\mathrm{~s}, 2 \mathrm{H}, \mathrm{tdc}), \delta / \mathrm{ppm}=2.87$, $2.70(\mathrm{~s}, 3 \mathrm{H}, \mathrm{DMF}), \delta / \mathrm{ppm}=7.92(\mathrm{~s}, 1 \mathrm{H}, \mathrm{DMF}), \delta / \mathrm{ppm}=8.14(\mathrm{~s}, 1 \mathrm{H}, \mathrm{fa})$. 


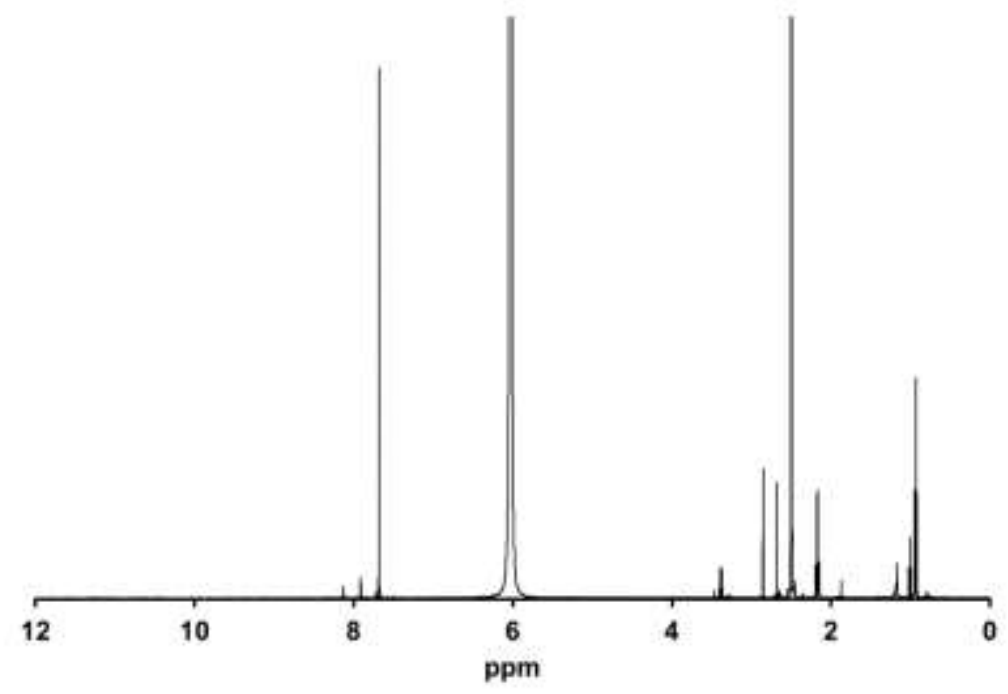

Figure S 35. ${ }^{1} \mathrm{H}-\mathrm{NMR}$ data of DUT-67-Pa.

${ }^{1} \mathrm{H}-\mathrm{NMR}:(\mathrm{DMSO} / \mathrm{DCl}): \delta / \mathrm{ppm}=0.94(\mathrm{t}, 3 \mathrm{H}, \mathrm{pa}), \delta / \mathrm{ppm}=2.17(\mathrm{q}, 2 \mathrm{H}, \mathrm{pa}), \delta / \mathrm{ppm}=7.68(\mathrm{~s}$, $2 \mathrm{H}, \mathrm{tdc}), \delta / \mathrm{ppm}=2.86,2.69(\mathrm{~s}, 3 \mathrm{H}, \mathrm{DMF}), \delta / \mathrm{ppm}=7.92(\mathrm{~s}, 1 \mathrm{H}, \mathrm{DMF}), \delta / \mathrm{ppm}=8.13(\mathrm{~s}, 1 \mathrm{H}$, fa), $\delta / p p m=1.00(t, 3 \mathrm{H}, \mathrm{EtOH}), \delta / \mathrm{ppm}=3.38(\mathrm{q}, 2 \mathrm{H}, \mathrm{EtOH})$.

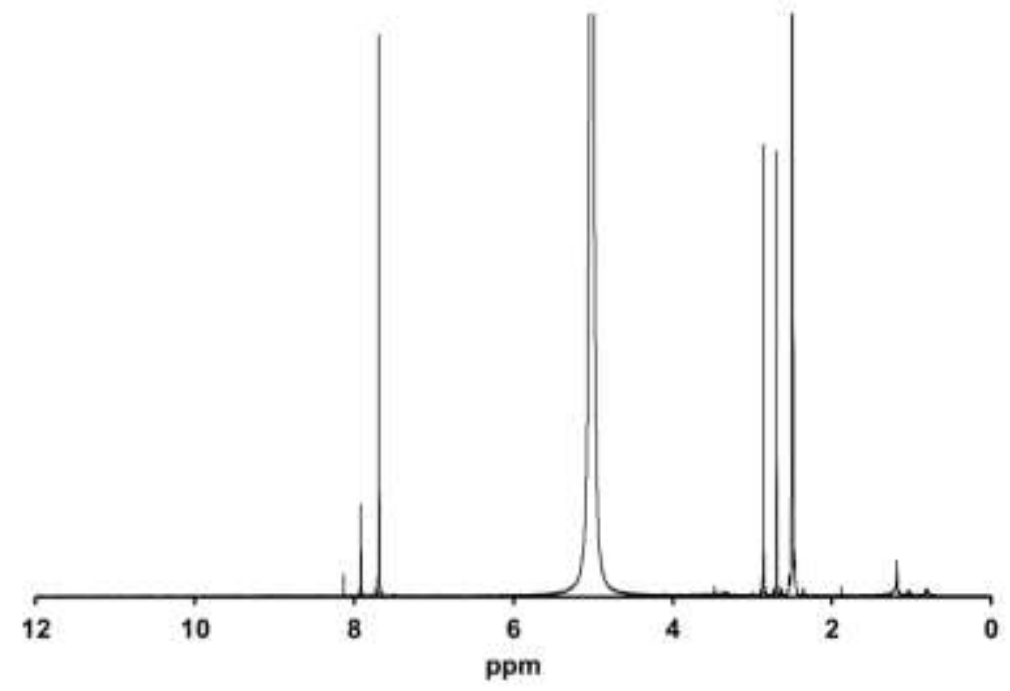

Figure S 36. ${ }^{1} \mathrm{H}-\mathrm{NMR}$ data of DUT-67-Tfa.

${ }^{1} \mathrm{H}-\mathrm{NMR}:(\mathrm{DMSO} / \mathrm{DCl}): \delta / \mathrm{ppm}=7.69$ (s, 2H, tdc), $\delta / \mathrm{ppm}=2.86,2.70(\mathrm{~s}, 3 \mathrm{H}, \mathrm{DMF}), \delta / \mathrm{ppm}=$ $7.92(\mathrm{~s}, 1 \mathrm{H}, \mathrm{DMF}), \delta / \mathrm{ppm}=8.13(\mathrm{~s}, 1 \mathrm{H}, \mathrm{fa})$ 


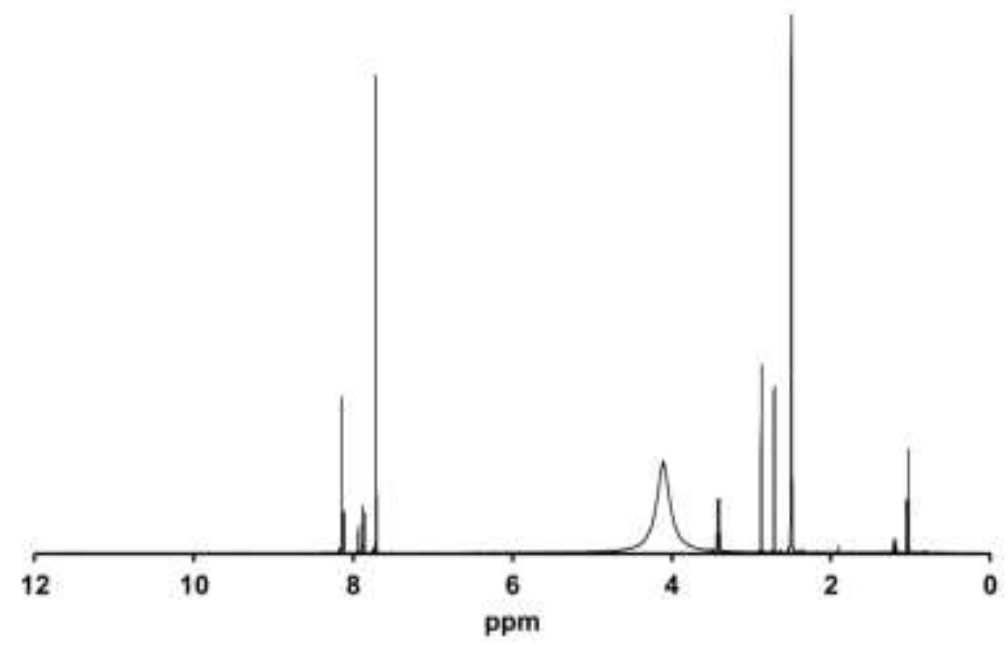

Figure S 37. ${ }^{1} \mathrm{H}-\mathrm{NMR}$ data of DUT-67-Tfmba.

${ }^{1} \mathrm{H}-\mathrm{NMR}:(\mathrm{DMSO} / \mathrm{DCl}): \delta / \mathrm{ppm}=7.87(\mathrm{~d}, 2 \mathrm{H}, \mathrm{tfmba}), \delta / \mathrm{ppm}=8.13(\mathrm{~d}, 2 \mathrm{H}, \mathrm{tfmba}), \delta / \mathrm{ppm}=$ $7.71(\mathrm{~s}, 2 \mathrm{H}, \mathrm{tdc}), \delta / \mathrm{ppm}=2.88,2.71(\mathrm{~s}, 3 \mathrm{H}, \mathrm{DMF}), \delta / \mathrm{ppm}=7.93(\mathrm{~s}, 1 \mathrm{H}, \mathrm{DMF}), \delta / \mathrm{ppm}=8.14$ $(\mathrm{s}, 1 \mathrm{H}, \mathrm{fa}), \delta / \mathrm{ppm}=1.04(\mathrm{t}, 3 \mathrm{H}, \mathrm{EtOH}), \delta / \mathrm{ppm}=3.42(\mathrm{q}, 2 \mathrm{H}, \mathrm{EtOH})$.

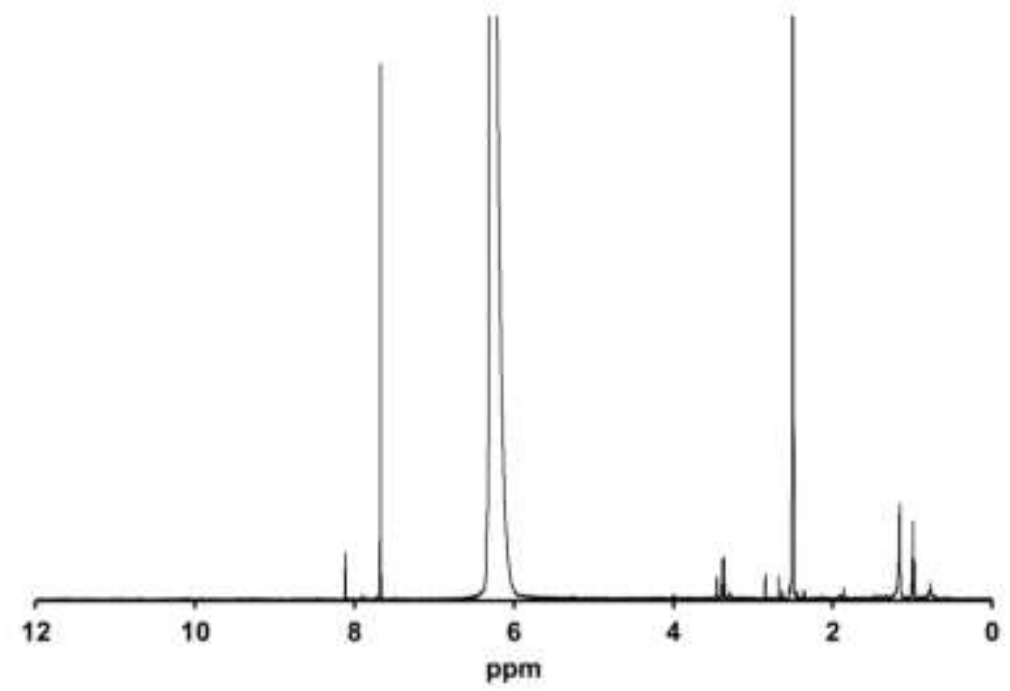

Figure S 38. ${ }^{1}$ H-NMR data of DUT-67-Pfba.

${ }^{1} \mathrm{H}-\mathrm{NMR}:(\mathrm{DMSO} / \mathrm{DCl}): \delta / \mathrm{ppm}=7.67(\mathrm{~s}, 2 \mathrm{H}, \mathrm{tdc}), \delta / \mathrm{ppm}=2.85,2.68(\mathrm{~s}, 3 \mathrm{H}, \mathrm{DMF}), \delta / \mathrm{ppm}=$ $7.89(\mathrm{~s}, 1 \mathrm{H}, \mathrm{DMF}), \delta / \mathrm{ppm}=8.12(\mathrm{~s}, 1 \mathrm{H}, \mathrm{fa}), \delta / \mathrm{ppm}=0.99(\mathrm{t}, 3 \mathrm{H}, \mathrm{EtOH}), \delta / \mathrm{ppm}=3.37(\mathrm{q}$ $2 \mathrm{H}, \mathrm{EtOH})$. 


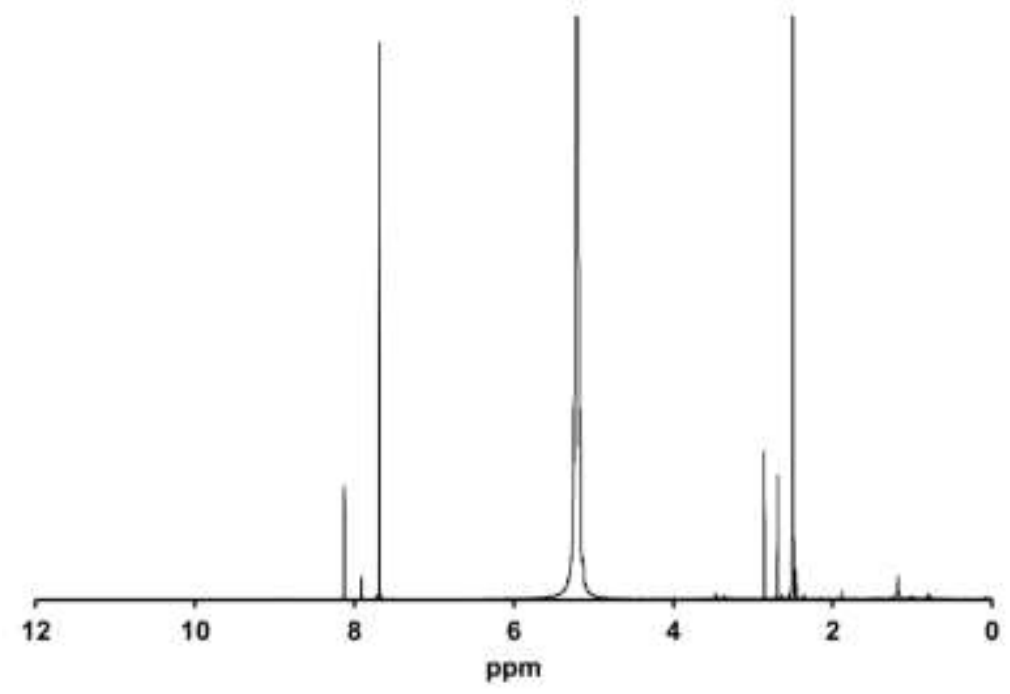

Figure S 39. ${ }^{1} \mathrm{H}-\mathrm{NMR}$ data of DUT-67-Pfoa.

${ }^{1} \mathrm{H}-\mathrm{NMR}:(\mathrm{DMSO} / \mathrm{DCl}): \delta / \mathrm{ppm}=7.9$ (s, 2H, tdc), $\delta / \mathrm{ppm}=2.86,2.69$ (s, 3H, DMF), $\delta / \mathrm{ppm}=$ $7.91(\mathrm{~s}, 1 \mathrm{H}, \mathrm{DMF}), \delta / \mathrm{ppm}=8.13(\mathrm{~s}, 1 \mathrm{H}, \mathrm{fa})$. 
S4.2: ${ }^{19}$ F-NMR data of fluorinated DUT-67.

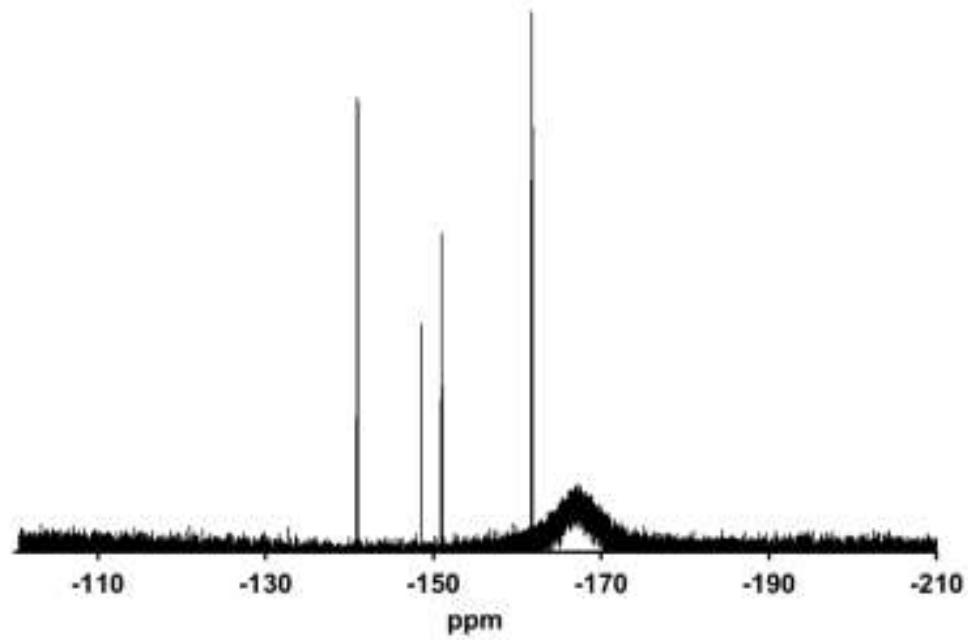

Figure S 40. ${ }^{19}$ F-NMR data of DUT-67-Pfba.

${ }^{19}$ F-NMR: (DMSO/DCl): $\delta / p p m=-140.94,-151.01,-161.79$.

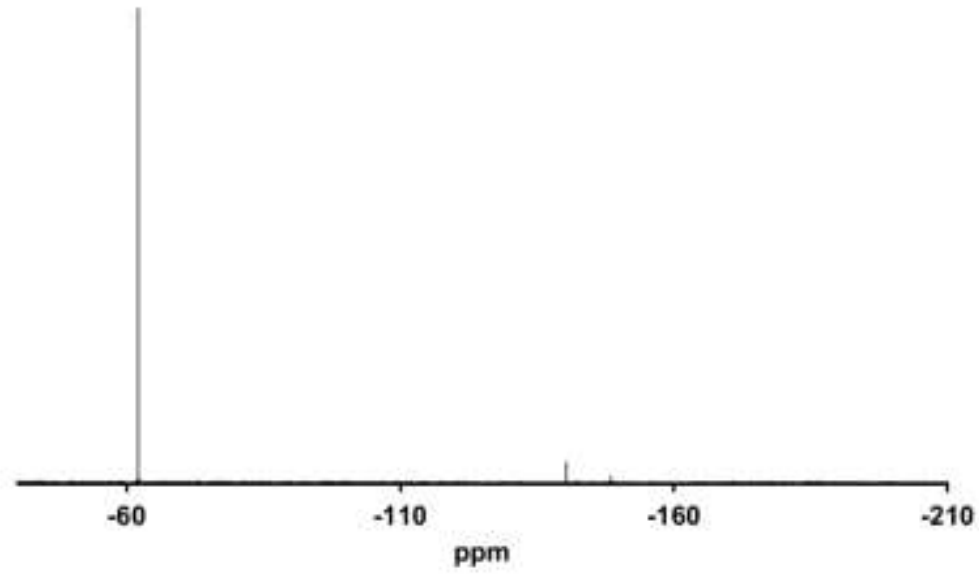

Figure S 41. ${ }^{19}$ F-NMR data of DUT-67-Tfmba.

${ }^{19}$ F-NMR: (DMSO/DCl): $\delta / \mathrm{ppm}=-62.17$. 


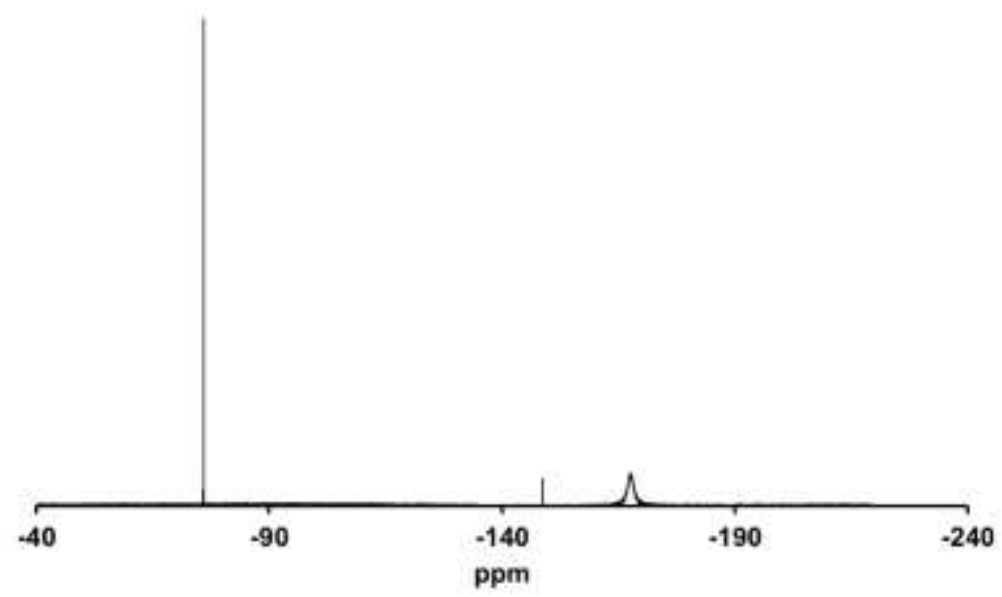

Figure S 42. ${ }^{19}$ F-NMR data of DUT-67-Tfa.

${ }^{19}$ F-NMR: (DMSO/DCl): $\delta / \mathrm{ppm}=-75.89$.

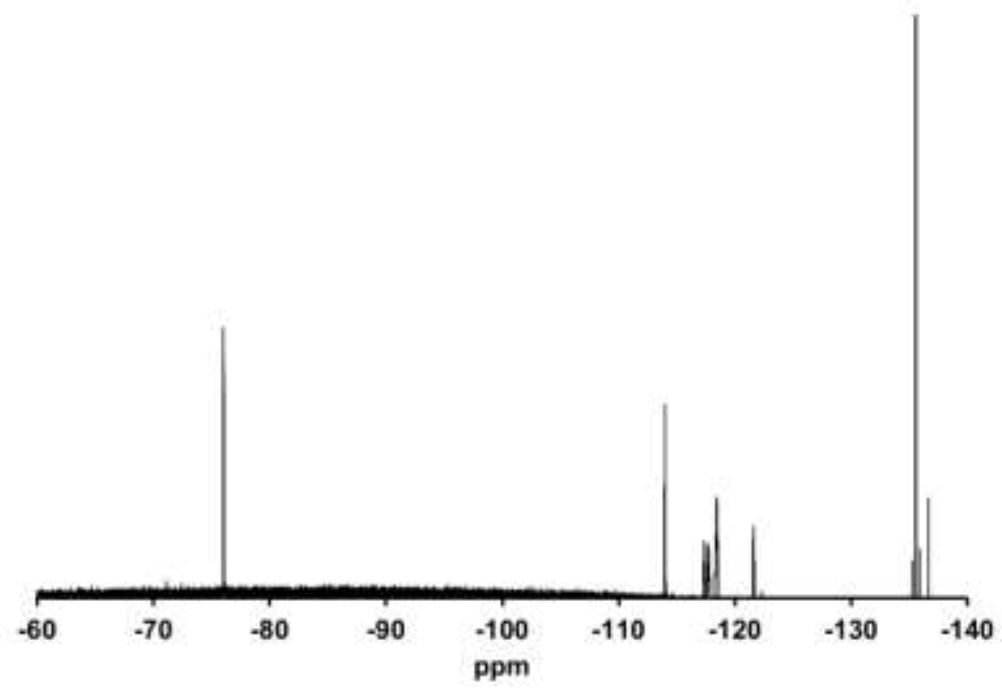

Figure S 43. ${ }^{19}$ F-NMR data of DUT-67-Pfoa.

${ }^{19}$ F-NMR: (DMSO/DCl): $\delta / \mathrm{ppm}=-76.03,-113.98,-117.54,-117.79,-118.43,-121.59,-$ 135.56. 


\section{S4.3: ${ }^{1}$ H-NMR data of the DUT-67 with the exchanged fluorinated modulators}

For the postsynthetic modification with fluorinated modulators, ethanol was used as solvent instead of DMF. The DMF signals in the spectra are drastically reduced, compared to the ones where DMF was used as solvent during the exchange.

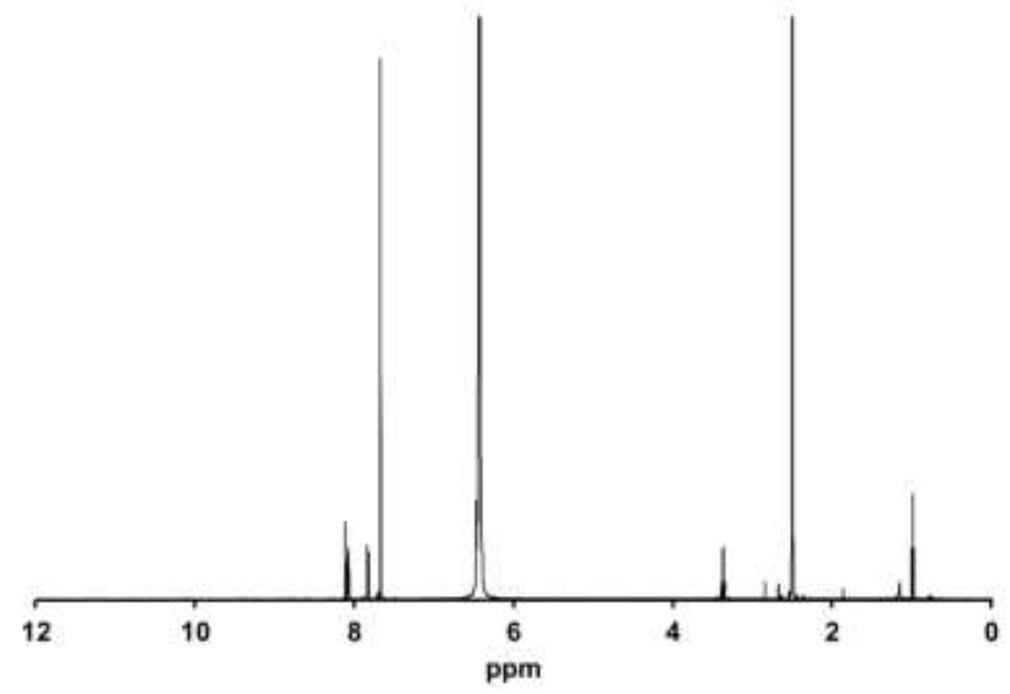

Figure S 44. ${ }^{1}$ H-NMR data of DUT-67-Tfmba, which was exchanged in an ethanol solution.

${ }^{1} \mathrm{H}-\mathrm{NMR}:(\mathrm{DMSO} / \mathrm{DCl}): \delta / \mathrm{ppm}=7.83(\mathrm{~d}, 2 \mathrm{H}, \mathrm{tfmba}), \delta / \mathrm{ppm}=8.08(\mathrm{~d}, 2 \mathrm{H}, \mathrm{tfmba}), \delta / \mathrm{ppm}=$ $7.67(\mathrm{~s}, 2 \mathrm{H}, \mathrm{tdc}), \delta / \mathrm{ppm}=2.84,2.67(\mathrm{~s}, 3 \mathrm{H}, \mathrm{DMF}), \delta / \mathrm{ppm}=7.9(\mathrm{~s}, 1 \mathrm{H}, \mathrm{DMF}), \delta / \mathrm{ppm}=8.11$ $(\mathrm{s}, 1 \mathrm{H}, \mathrm{fa}), \delta / \mathrm{ppm}=0.99(\mathrm{t}, 3 \mathrm{H}, \mathrm{EtOH}), \delta / \mathrm{ppm}=3.37(\mathrm{q}, 2 \mathrm{H}, \mathrm{EtOH})$

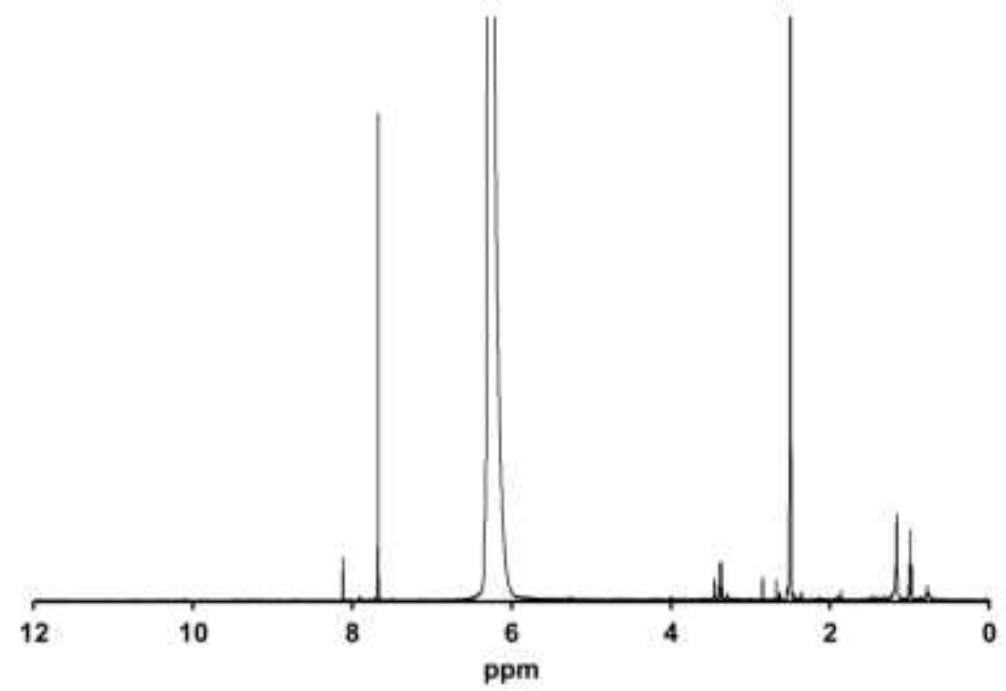

Figure S 45. ${ }^{1}$ H-NMR data of DUT-67-Pfba, which was exchanged in an ethanol solution. 
${ }^{1} \mathrm{H}-\mathrm{NMR}:(\mathrm{DMSO} / \mathrm{DCl}): \delta / \mathrm{ppm}=7.67(\mathrm{~s}, 2 \mathrm{H}, \mathrm{tdc}), \delta / \mathrm{ppm}=2.85,2.68(\mathrm{~s}, 3 \mathrm{H}, \mathrm{DMF}), \delta / \mathrm{ppm}=$ $7.9(\mathrm{~s}, 1 \mathrm{H}, \mathrm{DMF}), \delta / \mathrm{ppm}=8.12(\mathrm{~s}, 1 \mathrm{H}, \mathrm{fa}), \delta / \mathrm{ppm}=0.99(\mathrm{t}, 3 \mathrm{H}, \mathrm{EtOH}), \delta / \mathrm{ppm}=3.37(\mathrm{q}, 2 \mathrm{H}$, $\mathrm{EtOH})$.

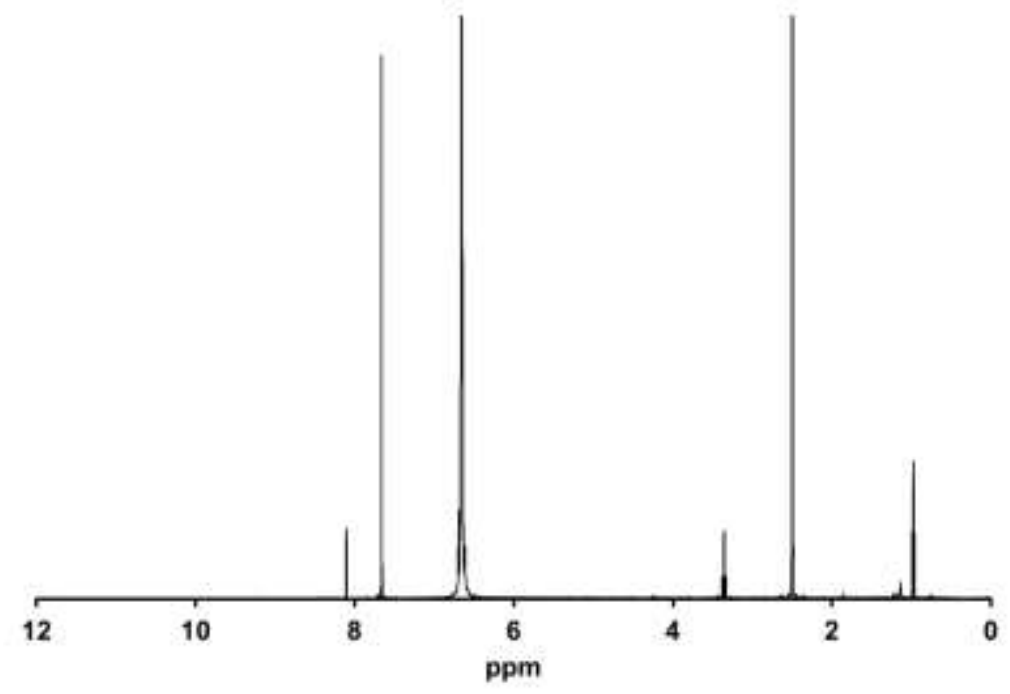

Figure S 46. ${ }^{1}$ H-NMR data of DUT-67-Tfa, which was exchanged in an ethanol solution.

${ }^{1} \mathrm{H}-\mathrm{NMR}:(\mathrm{DMSO} / \mathrm{DCl}): \delta / \mathrm{ppm}=7.66(\mathrm{~s}, 2 \mathrm{H}, \mathrm{tdc}), \delta / \mathrm{ppm}=8.11(\mathrm{~s}, 1 \mathrm{H}, \mathrm{fa}), \delta / \mathrm{ppm}=0.98(\mathrm{t}$, $3 \mathrm{H}, \mathrm{EtOH}), \delta / \mathrm{ppm}=3.36(\mathrm{q}, 2 \mathrm{H}, \mathrm{EtOH})$. 


\section{S5. Kinetic of the modulator exchange}

The kinetic of the exchange of Fa by Tfmba in DUT-67 was monitored by following the tdc:Tfmba ratio by ${ }^{1} \mathrm{H}-\mathrm{NMR}$ analysis. The DUT-67-Fa was stirred in Tfmba solution. After defined stirring time, a small amount of MOF was separated, washed with DMF several times to remove adsorbed modulator molecules. Afterwards, MOF was dissolved in deuterated DMSO containing $\mathrm{CsF} / \mathrm{DCl}$ mixture.

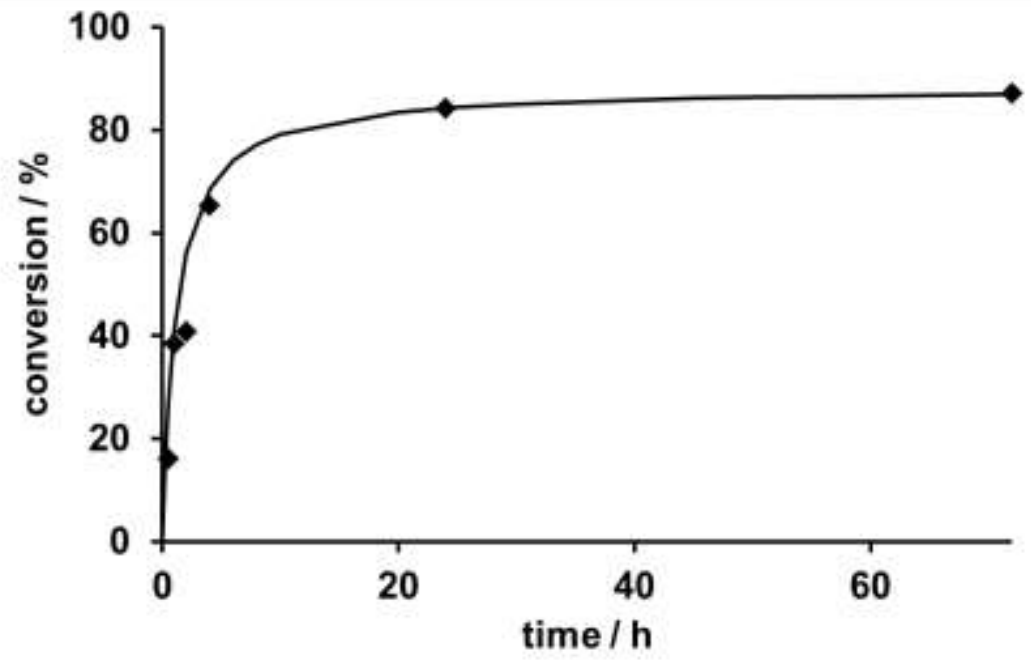

Figure S 47. Kinetic of the incorporation of Tfmba into DUT-67. 